\title{
Análise multitemporal das mudanças na cobertura vegetal ocorridas no município de Novo Repartimento, Pará
}

\author{
Multitemporal analysis of changes in vegetation cover in the municipality of Novo Repartimento, \\ Pará
}

Análisis multitemporal de cambios en la cobertura vegetal en el municipio de Novo Repartimento, Pará

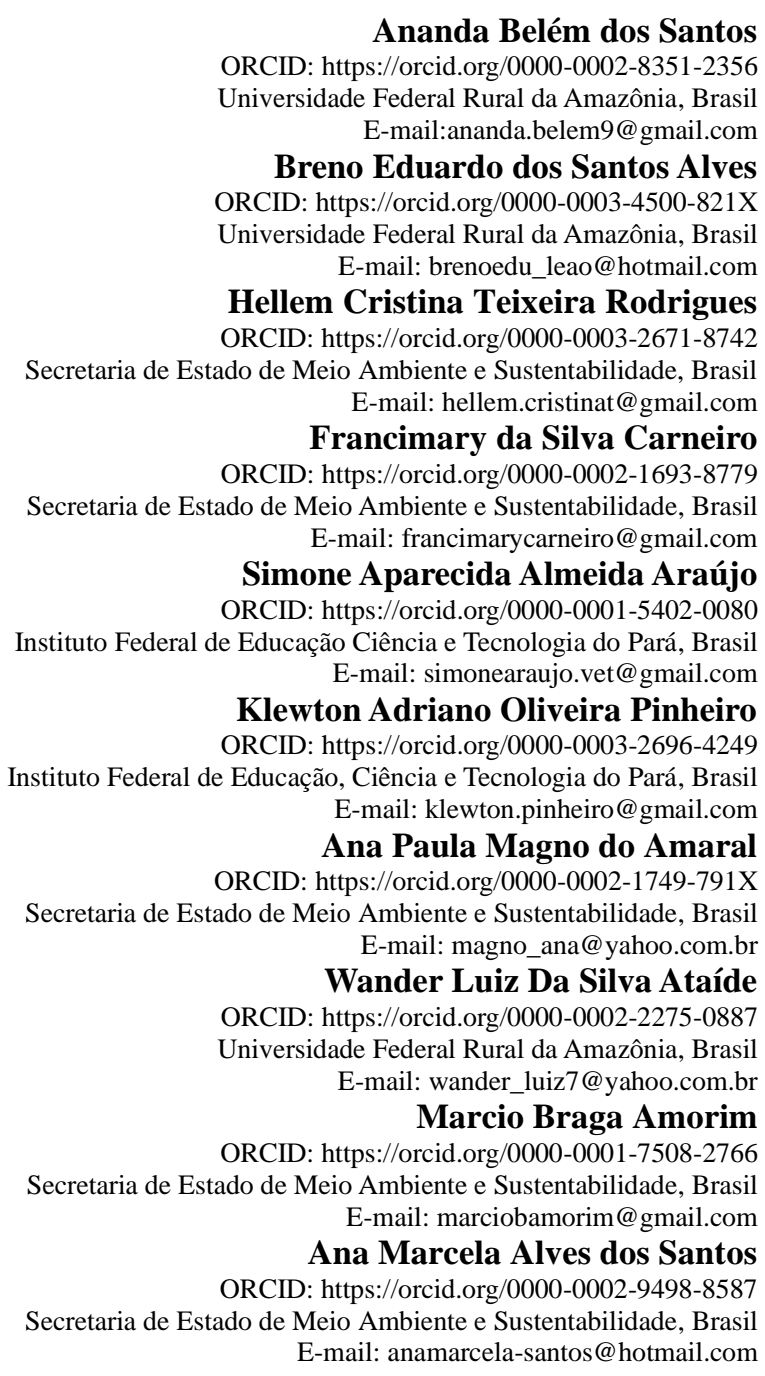

\section{Resumo}

Este trabalho objetivou analisar as alterações na cobertura vegetal do município de Novo Repartimento, Sudeste do Pará, para os anos de 2017, 2018 e 2019, com o uso do software ENVI 5.3 para realizar o processamento utilizando os métodos de classificação supervisionada e os respectivos procedimentos executados para realizar a análise na área de interesse, assim como utilizar o software ArcGIS 10.5 para quantificar e produzir os mapas finais. A área de estudo foi o município de Novo Repartimento, com a área delimitada, buscou-se realizar o download das cenas para os respectivos anos de 2017, 2018 e 2019. Foram baixadas três cenas do satélite Landsat 8, com as orbitas pontos: 224063, 224064 e 225063, para os respectivos anos. Ao analisar todas as classificações, pode-se concluir que para a área em estudo a classificação mais indicada é de Mahanalobis, porque conseguiu distinguir bem a floresta da área de 
vegetação secundária, assim como a área antrópica de nuvem, apresentando muito bem as estradas que passam entre o município.

Palavras-chave: Monitoramento; Classificação supervisionada; Método de Mahalanobis.

\begin{abstract}
This work aimed to analyze the changes in the vegetation cover of the municipality of Novo Repartimento, Southeast of Pará, for the years 2017, 2018 and 2019, using the ENVI 5.3 software to perform the processing using the supervised classification methods and the respective procedures performed to perform the analysis in the area of interest, as well as using ArcGIS 10.5 software to quantify and produce the final maps. The study area was the municipality of Novo Repartimento, with the delimited area, we sought to download the scenes for the respective years of 2017, 2018 and 2019. Three scenes were downloaded from the Landsat 8 satellite, with the orbits points: 224063,224064 and 225063, for the respective years. When analyzing all the classifications, it can be concluded that for the area under study the most suitable classification is Mahanalobis, because it managed to distinguish well the forest from the secondary vegetation area, as well as the anthropic cloud area, presenting very well the roads that pass between the municipality.
\end{abstract}

Keywords: Monitoring; Supervised classification; Mahalanobis method.

\title{
Resumen
}

Este trabajo tuvo como objetivo analizar los cambios en la cobertura vegetal del municipio de Novo Repartimento, Sudeste de Pará, para los años 2017, 2018 y 2019, utilizando el software ENVI 5.3 para realizar el procesamiento utilizando los métodos de clasificación supervisada y los respectivos procedimientos realizados. para realizar el análisis en el área de interés, así como utilizar el software ArcGIS 10.5 para cuantificar y producir los mapas finales. El área de estudio fue el municipio de Novo Repartimento, con el área delimitada se buscó descargar las escenas de los respectivos años 2017, 2018 y 2019. Se descargaron tres escenas del satélite Landsat 8, con los puntos de órbitas: 224063, 224064 y 225063, por los respectivos años. Al analizar todas las clasificaciones, se puede concluir que para el área en estudio la clasificación más adecuada es Mahanalobis, pues logró distinguir bien el área de bosque del área de vegetación secundaria, así como el área de nubosidad antrópica, presentando muy bien los caminos. que transcurren entre el municipio.

Palabras clave: Monitoreo; Clasificación supervisada; Método Mahalanobis.

\section{Introdução}

O Bioma Amazônia ocupa cerca de 49\% do território brasileiro (Figura 1). A Amazônia possui a maior -floresta tropical do mundo, equivalente a 1/3 das reservas de -florestas tropicais úmidas que abrigam a maior quantidade de espécies da -flora e da fauna.

Figura 1. Mapa do Brasil com os seus respectivos Biomas.

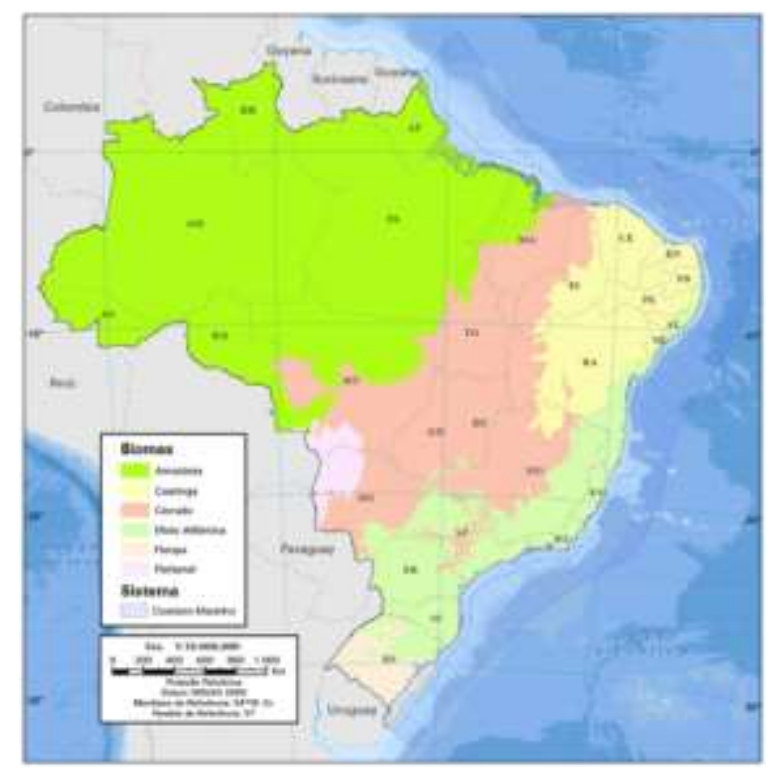

Fonte: IBGE (2022). 
Contém 20\% da disponibilidade mundial de água e grandes reservas minerais (IBGE, 2022), no entanto, as atividades antrópicas têm importante papel na diminuição desse bioma, principalmente pela introdução da agropecuária e agricultura intensiva (Souza Filho,2006, Santana \& Araújo 2017, Ribeiro 2022,). Isso acontece principalmente na região do "Arco do desmatamento", local onde a fronteira agrícola avança em direção à floresta e também onde se encontram os maiores índices de desmatamento da Amazônia. São 500 mil km² de terras que vão do leste e sul do Pará em direção oeste (IPAM, 2015).

O Brasil ainda é um dos países remanescentes do mundo que permanecem agregando novos territórios sem respeitar as populações nativas da região amazônica, provocando segregação entre a população, principalmente, as que pertencem a classes menos favorecidas, e causando transformações diversas tanto no meio rural quanto no urbano (Rosário 2021, ribeiro 2021, Souza 2021, Tavares 2021). Esse evento, intensificado pelos acontecimentos do cenário atual, apresentando a necessidade socioeconômica e, pelo outro ponto de vista, as consequências ambientais, torna difícil o encontro de um modelo que mantenha o equilíbrio entre ser socialmente justo e ambientalmente correto (Passos, 2017).

Uma das formas de diminuir a pressão humana sobre a Amazônia é utilizar o monitoramento contínuo da região, como faz o Instituto do Homem e Meio Ambiente da Amazônia - Imazon, por meio de imagens de satélite, detectando, quantificando e monitorando o desmatamento, a degradação florestal, a exploração madeireira, as estradas não oficiais e outras formas de pressão (IMAZON, 2018, INPE 2019).

O Município de Novo repartimento apresenta $14.7 \%$ de domicílios com esgotamento sanitário adequado, $6.9 \%$ de domicílios urbanos em vias públicas com arborização e $0.6 \%$ de domicílios urbanos em vias públicas com urbanização adequada (presença de bueiro, calçada, pavimentação e meio-fio). Quando comparado com os outros municípios do estado, fica na posição 54 de 144, 134 de 144 e 89 de 144, respectivamente (IBGE 2021). No período de 2000 a 2013, 745.570 hectares de áreas desmatadas foram detectadas em Novo Repartimento. Já o desmatamento total acumulado referente ao ano de 2013 foi de 735.833,50 ha, representando assim 48\% da área total do município. Detectou-se considerável evolução nas áreas desmatadas compreendidas no município, refletindo assim a necessidade de medidas intensas e eficazes no combate e prevenção ao desmatamento nessa região (Farias et al 2015, Farias 2016, Farias et al 2017, Rosário 2020).

Este trabalho objetivou analisar as alterações na cobertura vegetal do município de Novo Repartimento, Sudeste do Pará, para os anos de 2017, 2018 e 2019, com o uso do software ENVI 5.3 para realizar o processamento utilizando os métodos de classificação supervisionada e os respectivos procedimentos executados para realizar a análise na área de interesse, assim como utilizar o software ArcGIS 10.5 para quantificar e produzir os mapas.

\section{Metodologia}

A área de estudo foi o município de Novo Repartimento, com a área delimitada, buscou-se realizar o download das cenas para os respectivos anos de 2017, 2018 e 2019. Foram baixadas três cenas do satélite Landsat 8, com as orbitas pontos: 224063, 224064 e 225063, para os respectivos anos.

Dando início ao processamento no software ENVI 5.3 (SulSoft, 2022), abrindo imagem por imagem pelo arquivo com extensão MTL para obter todas as bandas de forma automática, para posteriormente realizar a correção atmosférica, primeiro processando a radiância e depois a reflectância da imagem, o processamento de reflectância pode se considerar o mais trabalhoso de todos.

Após a correção, foi realizado o mosaico, juntando as três cenas para formar uma área total que compreendesse o município todo foram feito o recorte da imagem utilizando o limite municipal como parâmetro, apesar de não ser indicado realizar o recorte nesse momento, foi necessário por conta das condições computacionais que não eram favoráveis ao processamento. Foi feito o processamento para os três anos, resultando na Figura 2. 
Figura 2: A área de estudo em 2017, 2018 e 2019 plotadas no ENVI.

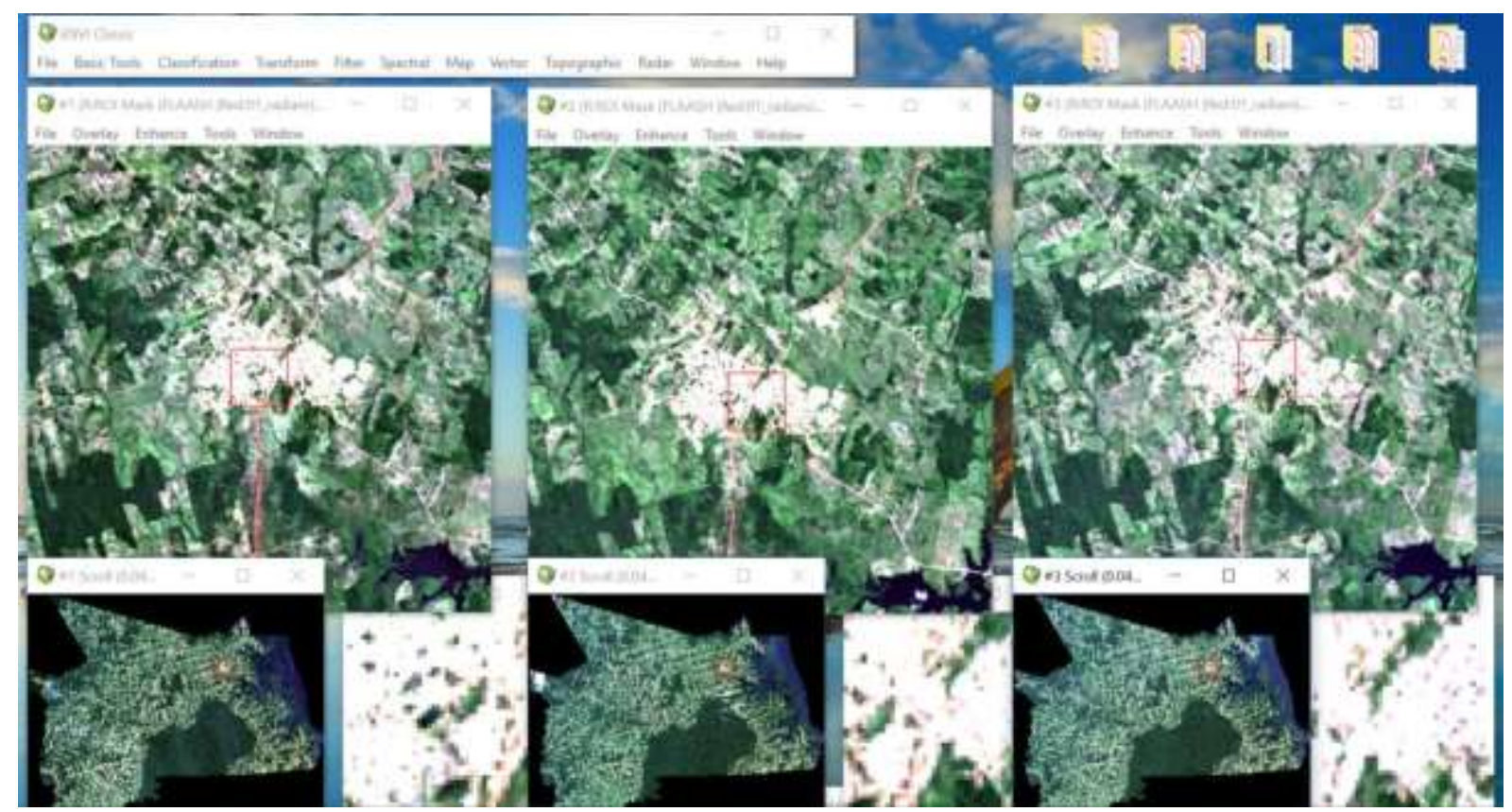

Fonte: Autores.

Com a área especifica, foram coletadas as amostras com as seguintes classes: 1 - Água, 2 - floresta, 3 - vegetação secundária, 4 - solo exposto e 5 - área antrópica. Sendo extraído amostras para subsidiar os métodos de classificação e também para análise de cada ano.

Foram realizados os métodos de classificação supervisionada: 01_Parallelepiped; 02_Mahalanobis; 03_Minimum e 04_Maxver para cada ano para analisar qual o melhor método a ser empregado para realizar a quantificação das modificações na cobertura vegetal sofrida dentro dos limites do município de Novo Repartimento.

Com todas as classificações executadas, escolheu-se o método de Mahalanobis(Mahalanobis, 1936) para se realizar os processamentos posteriores. Exportando as imagens do ENVI 5.3 para a extensão TIFF, com as imagens na extensão compatível com o ArcGIS (Esri, 2016), foi utilizando o ArcGIS para converter a imagem em vetores, para depois calcular a geometria de cada polígono calculando a área em metros quadrados, seguindo pela utilização da calculadora para calcular a área em hectares. Feito isso, foi utilizado a ferramenta de seleção por atributos para escolher a classe e ao selecionar a classe, foi calculada a estatística para se ter em mão os dados em hectares das classes. Para melhor apresentar, a quantificação foi inserida no Excel para gerar as análises em gráficos exposta nos resultados.

\section{Resultados e Discussão}

Para o ano de 2017, foram extraídas as classes de: 1 - Água, 2 - floresta, 3 - vegetação secundária, 4 - solo exposto e 5 - área antrópica. Foi construída a estatísticas das classes, para verificar quais bandas apresentavam a melhor resposta espectral da superfície e se as classes não estariam se confundindo, como segue na Figura 3. 
Figura 3: Estatísticas de cada classe considerando as bandas para o ano de 2017.

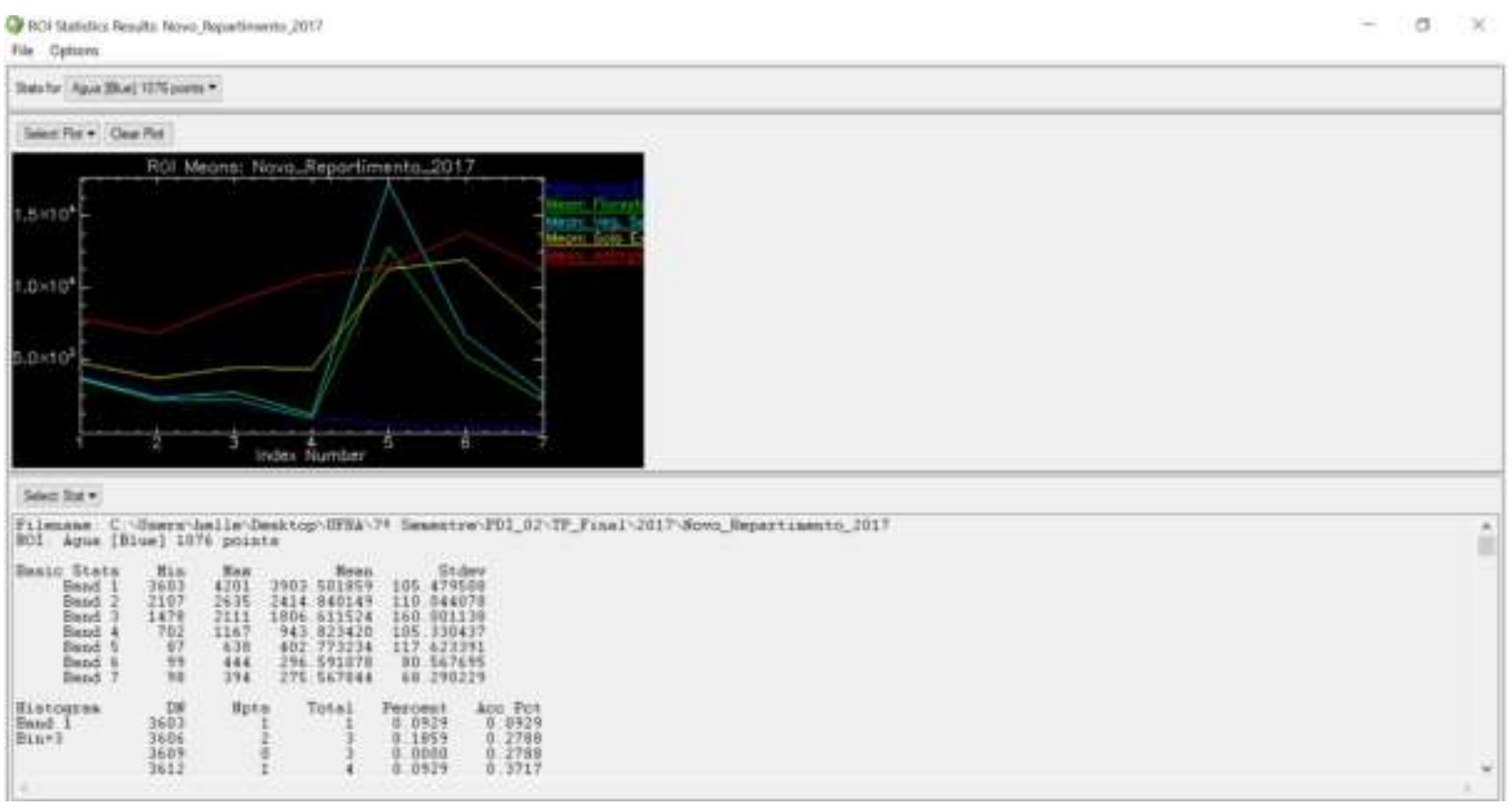

Fonte: Autores.

$\mathrm{Na}$ Figura 4, tem-se a demonstração das curvas espectrais geradas a partir das amostras, com a primeira classe representada pela linha de cor azul, referente a água, tendo seu pico na banda 2 do landsat, e depois apresentando um decaimento, isso se explica pela densidade da água, absorvendo mais energia, ou seja, quanto mais próximo do infravermelho menor a reflectância da mesma.

Depois, a curva de maior resposta de cor cyan, que representa a vegetação segundaria justamente na banda banda 5 do landsat 8 , que representa a banda do infravermelho próximo por conta da estrutura celular das folhas, ou seja, os espaços intercelulares presentes na camada mesófila que possibilitam (Kawakubo, 2019). Ainda na banda 5, tem-se a classe de floresta com a linha da cor verde, tendo uma menor resposta que a vegetação secundaria, mas isso se explica pela menor produção de biomassa, ou seja, energia.

Seguido pelas classes de solo exposto e área antrópica, essas tendo seu maior pico na banda 6, infravermelho médio, por conta da maior resposta por conta da superfície lisa refletir mais energia que superfícies rugosas (florestas). Tendo maior destaque para a área antrópica por conta dos telhados de materiais altamente reflexivos como alumínio.

Com as amostras de cada classe coletada, foi realizado o processamento utilizando os 4 métodos já citados, resultando nas Figuras 3, 4, 5 e 6. Fundamentais para o processo de escolha da classificação que será usada no desenvolvimento deste trabalho.

Iniciando pelo método de Paralelepípedo, considerado mais simples por considerar duas bandas, com máximo e mínimo de reflectância. Considerando uma caixa de paralaxe. Por isso, esse método apresenta problema com ambiguidades e os pixels que estão localizados fora da caixa são desconsiderados, ou seja, não são classificados, ficando pretos, fenômeno que pode ser visto na Figura 3 perfeitamente (Notas, 2019). 
Research, Society and Development, v. 11, n. 2, e5511222696, 2022

(CC BY 4.0) | ISSN 2525-3409 | DOI: http://dx.doi.org/10.33448/rsd-v11i2.22696

Figura 4: Método de paralelepípedo para o ano de 2017.

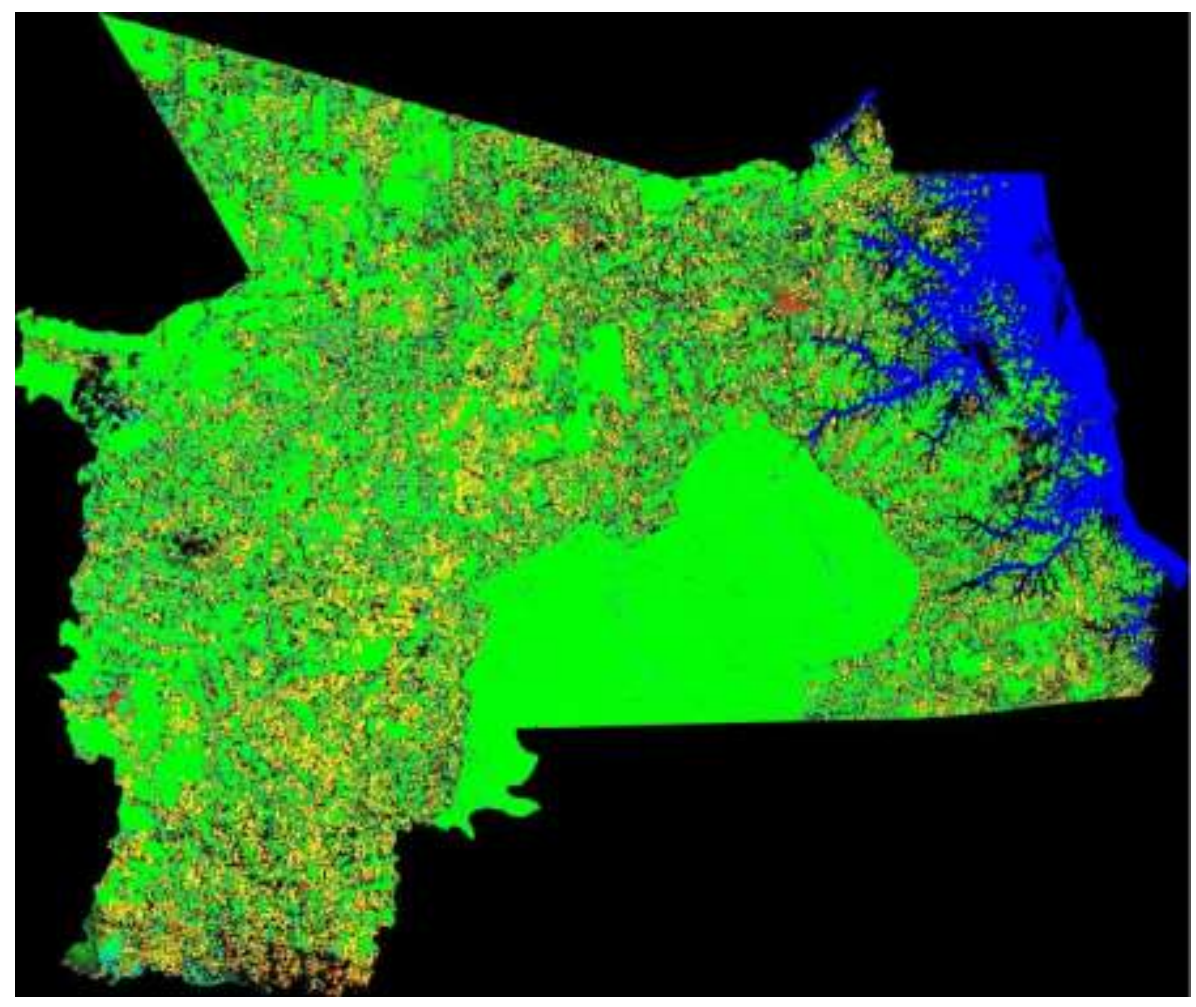

Fonte: Autores.

Já o próximo método, que é a distância mínima, utiliza o máximo e o mínimo de cada banda e nos pixels dispersos considera a menor distância do pixel para a caixa de análise, o que miniminiza desconsiderar os pixel e atribui uma classificação fazendo referência ao pixel mais próximo. Com isso, na Figura 5 não se encontra pixel pretos, pois os mesmos não foram classificados (Notas, 2019). 
Figura 5: Método de mínima distância para o ano de 2017.

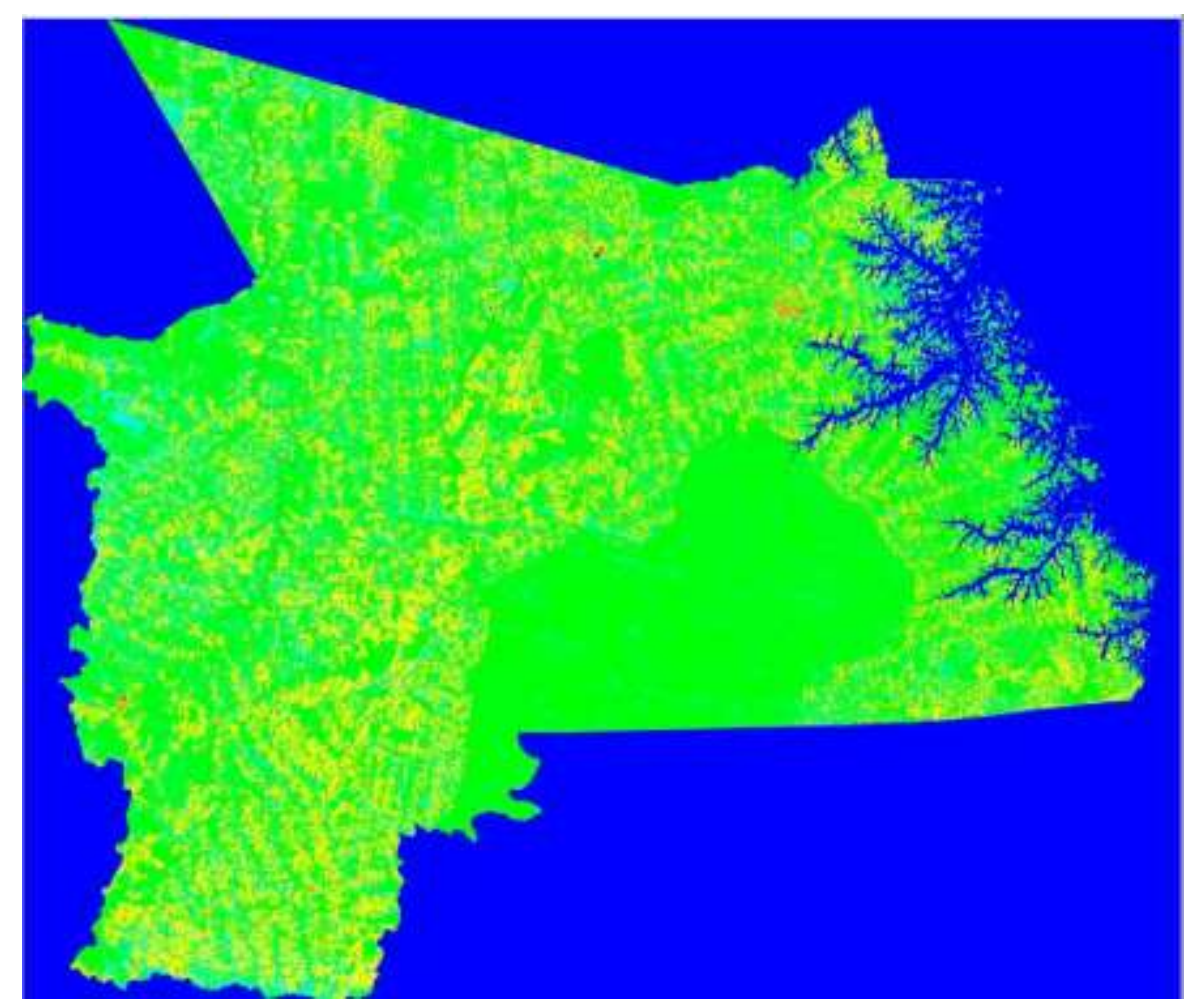

Fonte: Autores.

O método de Mahalanobis é, simplesmente, a medida da distância do pixel na posição x do espaço multidimensional ao centro da classe, dividida pelo comprimento do elipsóide na direção de x. Isso tem a propriedade de minimizar a distância do ponto ao centro de média. É dessa forma um classificador de distância sensitivo à direção que usa estatística para cada classe, o que o faz similar ao classificador por máxima verossimilhança, mas assume que todas as classes tem covariâncias iguais, com isso, consegue minimizar variações causadas por áreas especificas que apresentem alteração na resposta, como é o caso encontrado quando se tem muito a presença de nuvens, resultando no produto da Figura 6 (Menezes \& Almeida, 2012). 
Research, Society and Development, v. 11, n. 2, e5511222696, 2022

(CC BY 4.0) | ISSN 2525-3409 | DOI: http://dx.doi.org/10.33448/rsd-v11i2.22696

Figura 6: Método de Mahalanobis para o ano de 2017.

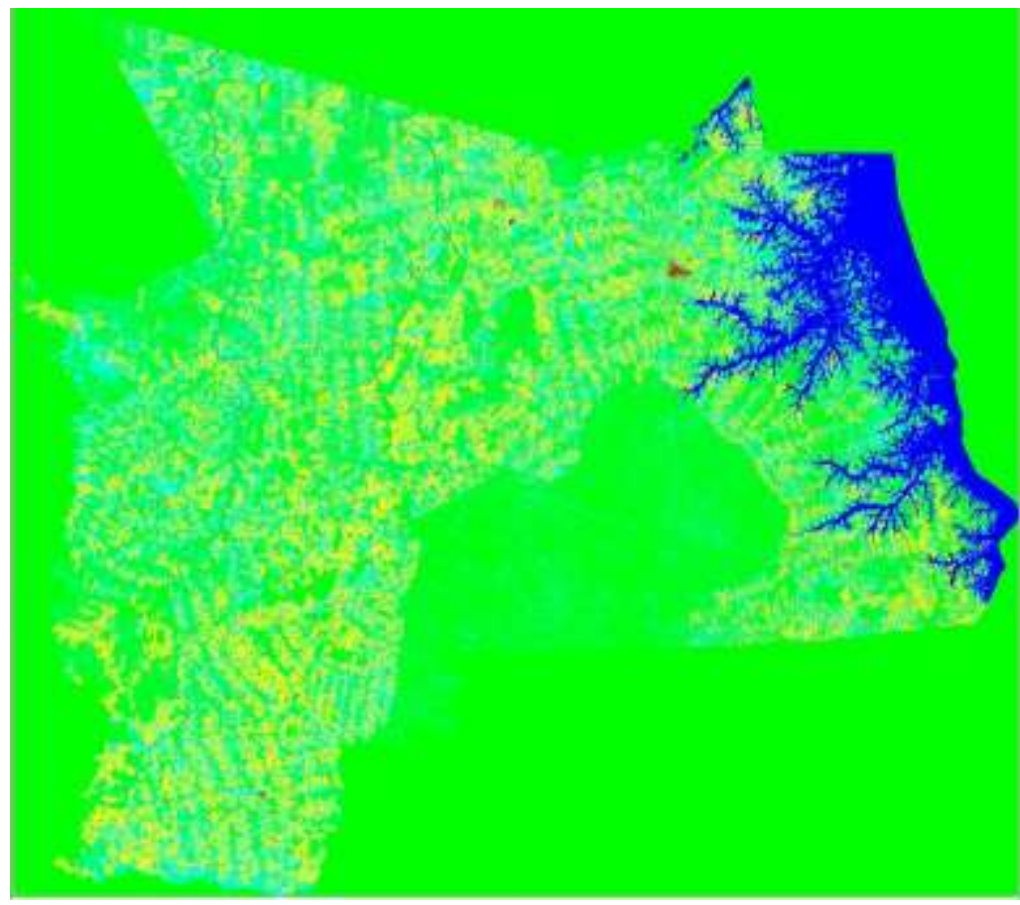

Fonte: Autores.

O último classificador utilizado aqui foi por máxima verossimilhança (MaxVer), que considera a ponderação das distâncias entre as médias dos valores dos pixels das classes, utilizando parâmetros estatísticos. Assume que todas as bandas têm distribuição normal e calcula a probabilidade de um dado pixel pertencer a uma classe específica (INPE, 2008). Mas, por conta de todos os métodos estatísticos, imagens com nuvens chega a comprometer o método, porque se confunde muito a classe de nuvem com outras (Figura 7).

Figura 7: Método de MaxVer para o ano de 2017.

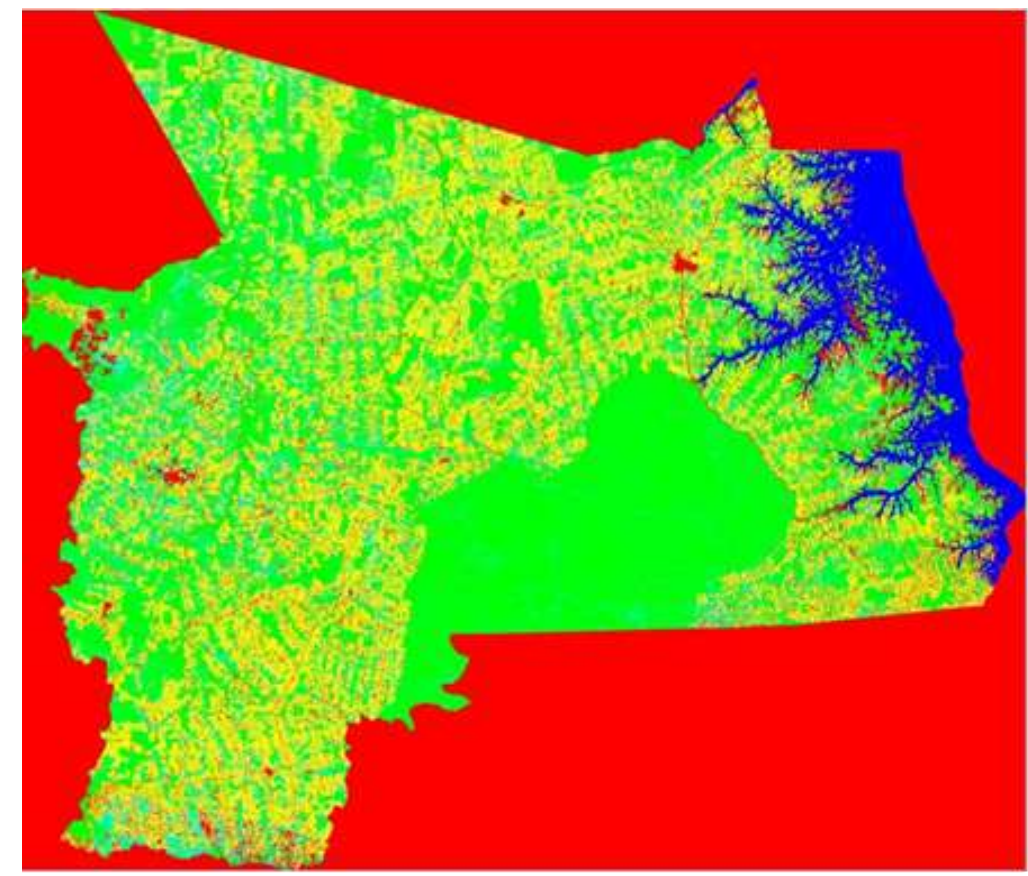

Fonte: Autores. 
Para melhor representar os métodos, foi criado uma visualização simultânea dos classificadores, como demonstra-se na Figura 8.

Figura 8: Visualização simultânea dos 4 métodos para o ano de 2017.

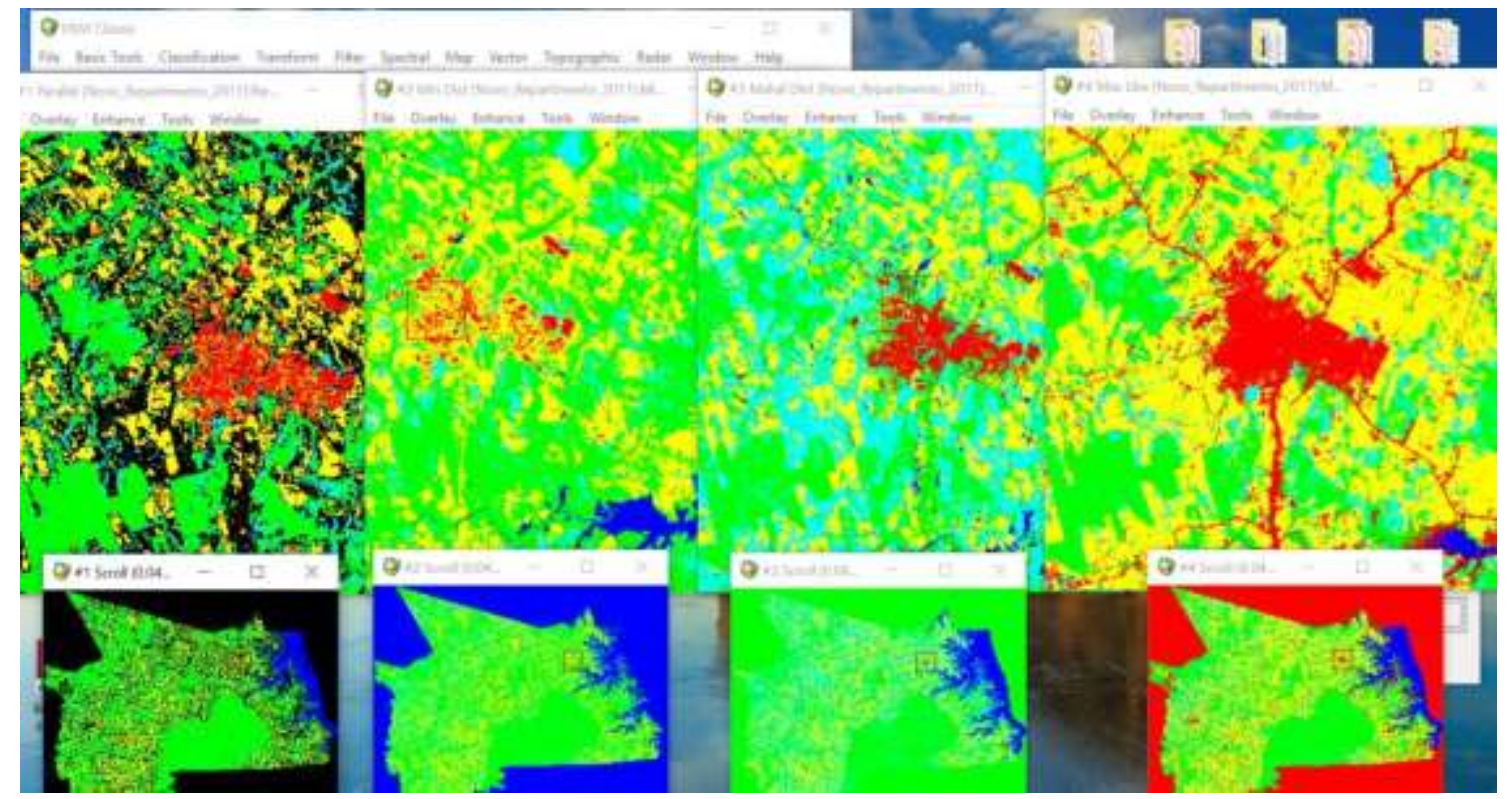

Fonte: Autores.

Para o ano de 2018, foi utilizado as mesmas classes: Água, floresta, vegetação secundária, solo exposto e área antrópica. Foi construída a estatísticas das classes, para verificar quais bandas apresentavam a melhor resposta espectral da superfície e se as classes não estariam se confundindo, como segue na Figura 9.

Figura 9: Estatísticas de cada classe considerando as bandas para o ano de 2018.

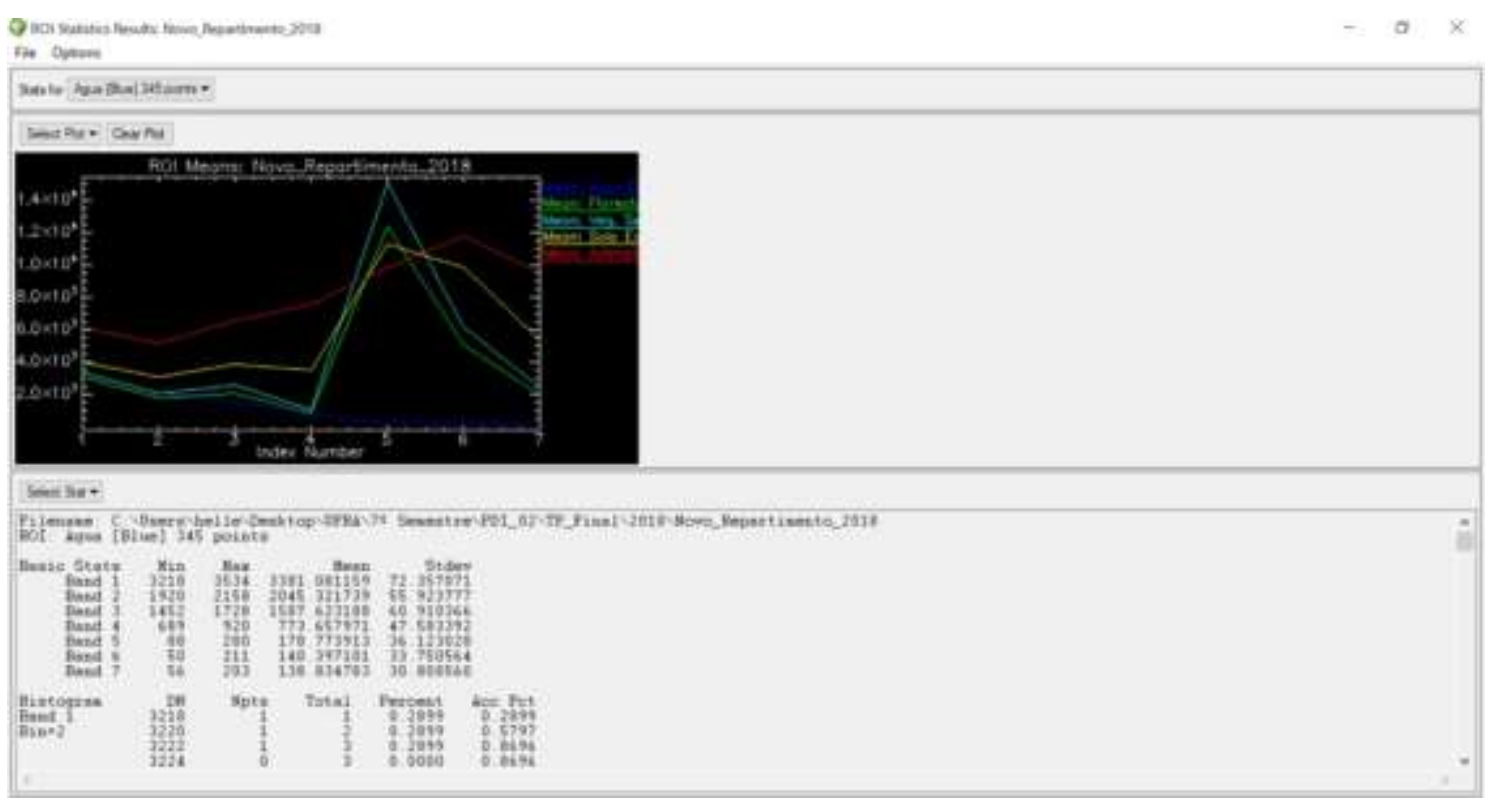

Fonte: Autores. 
Na discussão desta estatísticas apresenta resultado muito parecido com os apresentados para o ano de 2017(Figura 9), tendo uma anomalia na classe de solo exposto, que aparece muito próximo do pico de floresta, no entanto, isso só acontece na banda 5 do landsat, nas outras bandas há uma boa diferenciação.

Com as amostras de cada classe coletada, foi realizado o processamento utilizando os 4 métodos já citados, resultando nas Figuras 10, 11, 12 e 13. Como já foi realizado a explicação de cada método para o ano de 2017, só apresentou-se os resultados dos classificadores, ou seja, demonstrou-se visualmente os parâmetros de analises considerados, como demonstrados nas figuras.

Figura 10: Método de paralelepípedo para o ano de 2018.

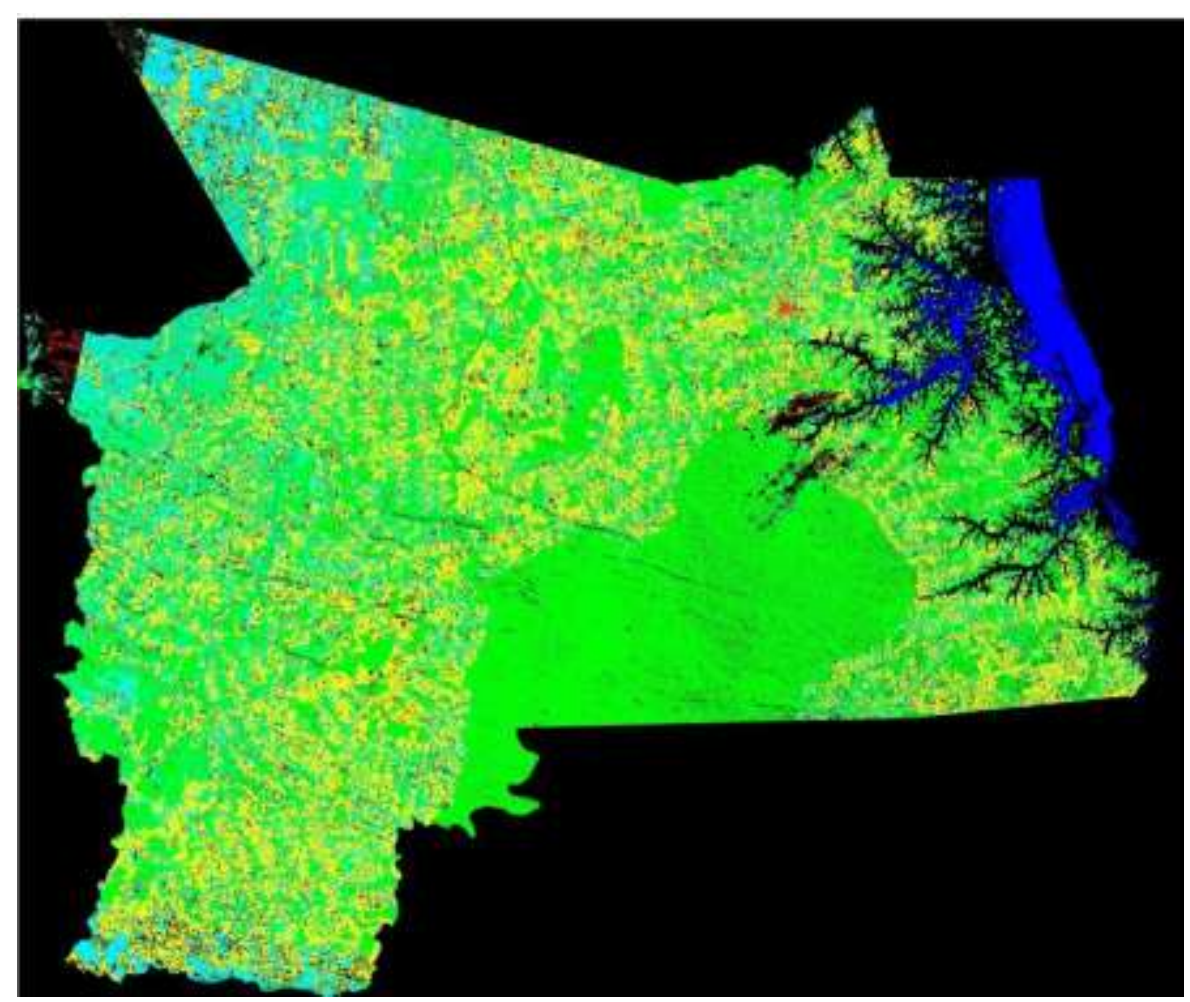

Fonte: Autores. 
Research, Society and Development, v. 11, n. 2, e5511222696, 2022

(CC BY 4.0) | ISSN 2525-3409 | DOI: http://dx.doi.org/10.33448/rsd-v11i2.22696

Figura 11: Método de mínima distância para o ano de 2018.

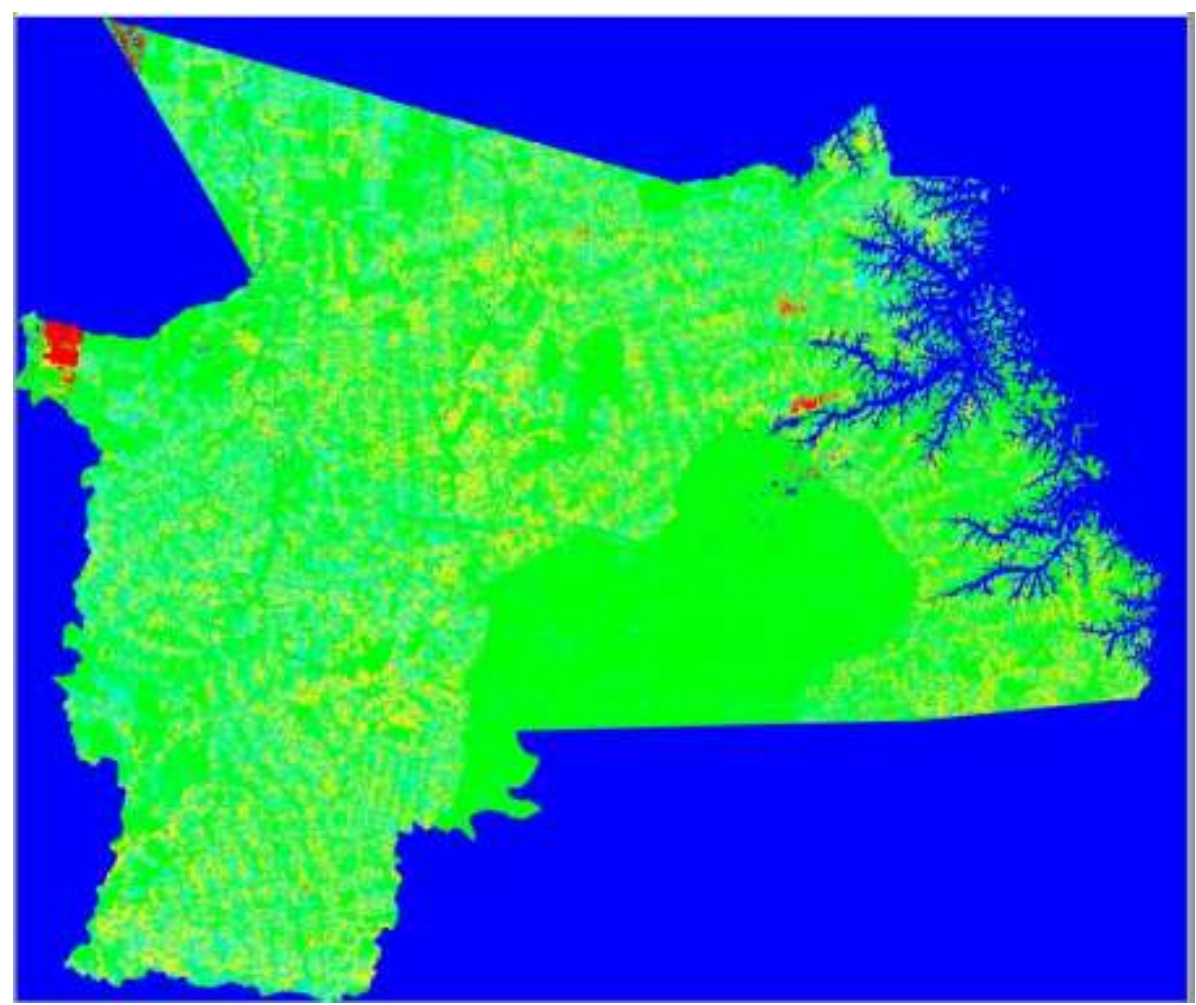

Fonte: Autores.

Figura 12: Método de Mahalanobis para o ano de 2018.

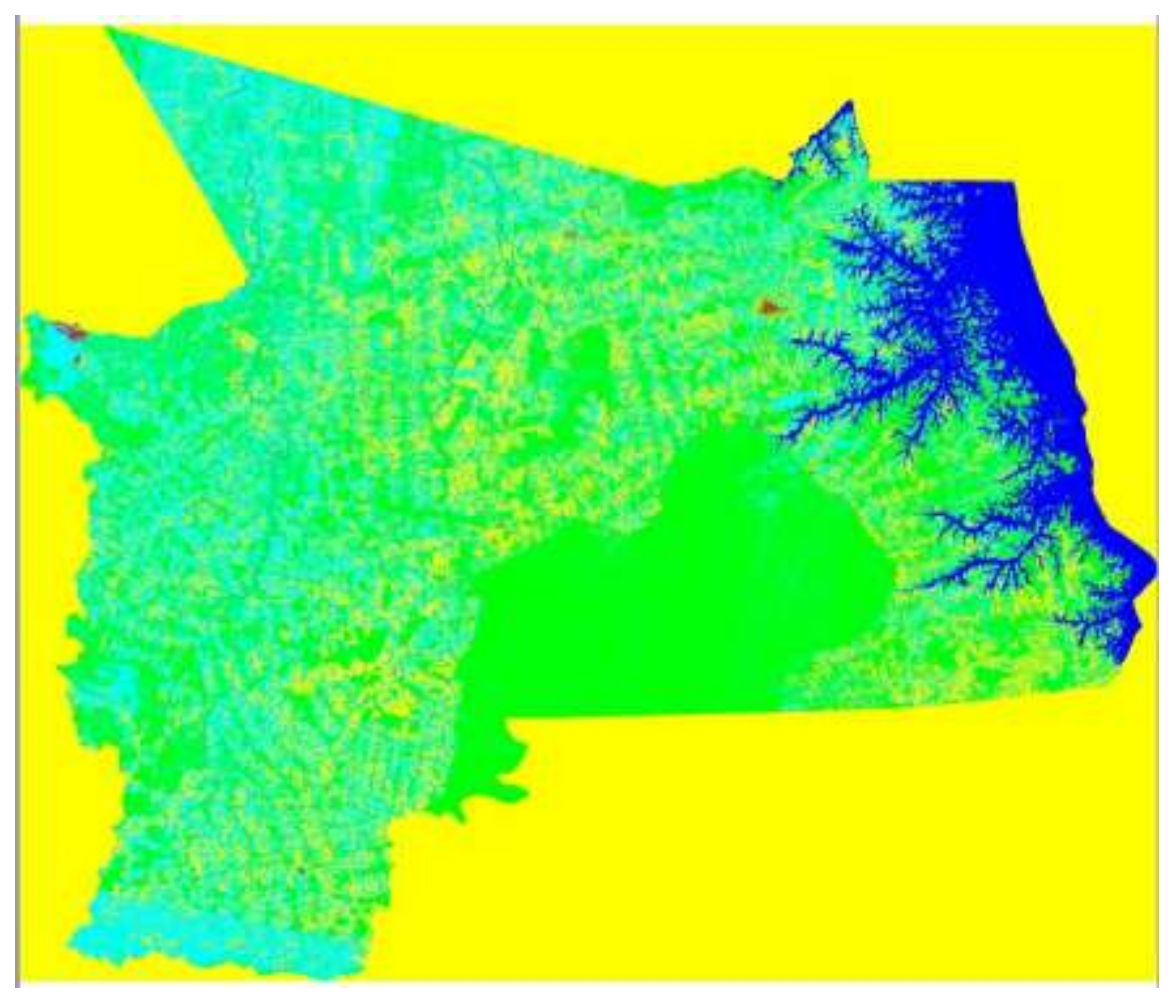

Fonte: Autores. 
Research, Society and Development, v. 11, n. 2, e5511222696, 2022

(CC BY 4.0) | ISSN 2525-3409 | DOI: http://dx.doi.org/10.33448/rsd-v11i2.22696

Figura 13: Método de MaxVer para o ano de 2018.

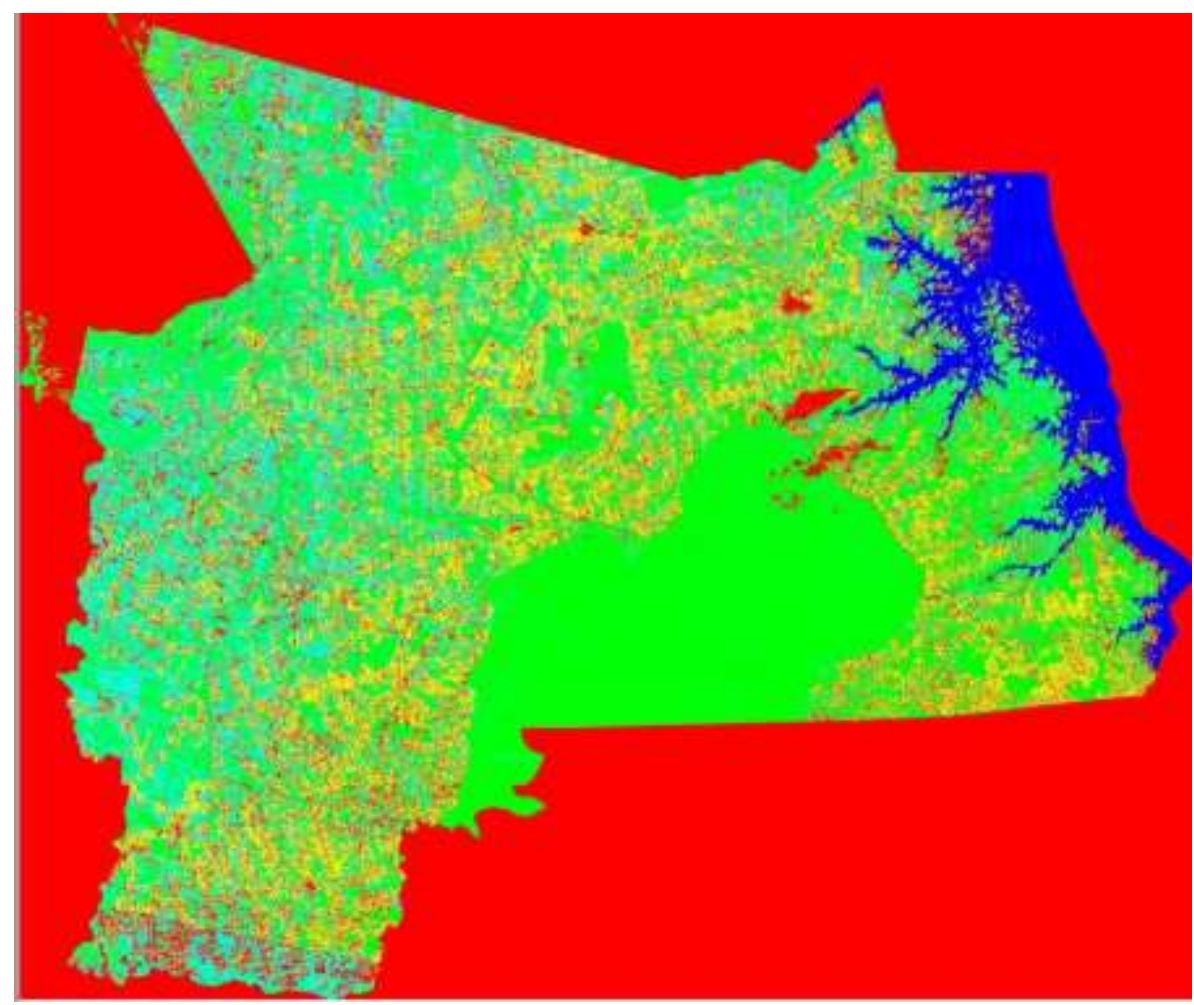

Fonte: Autores.

Para melhor representar os métodos, foi criado uma visualização simultânea, como segue na Figura 14.

Figura 14: Visualização simultânea dos 4 métodos para o ano de 2018.

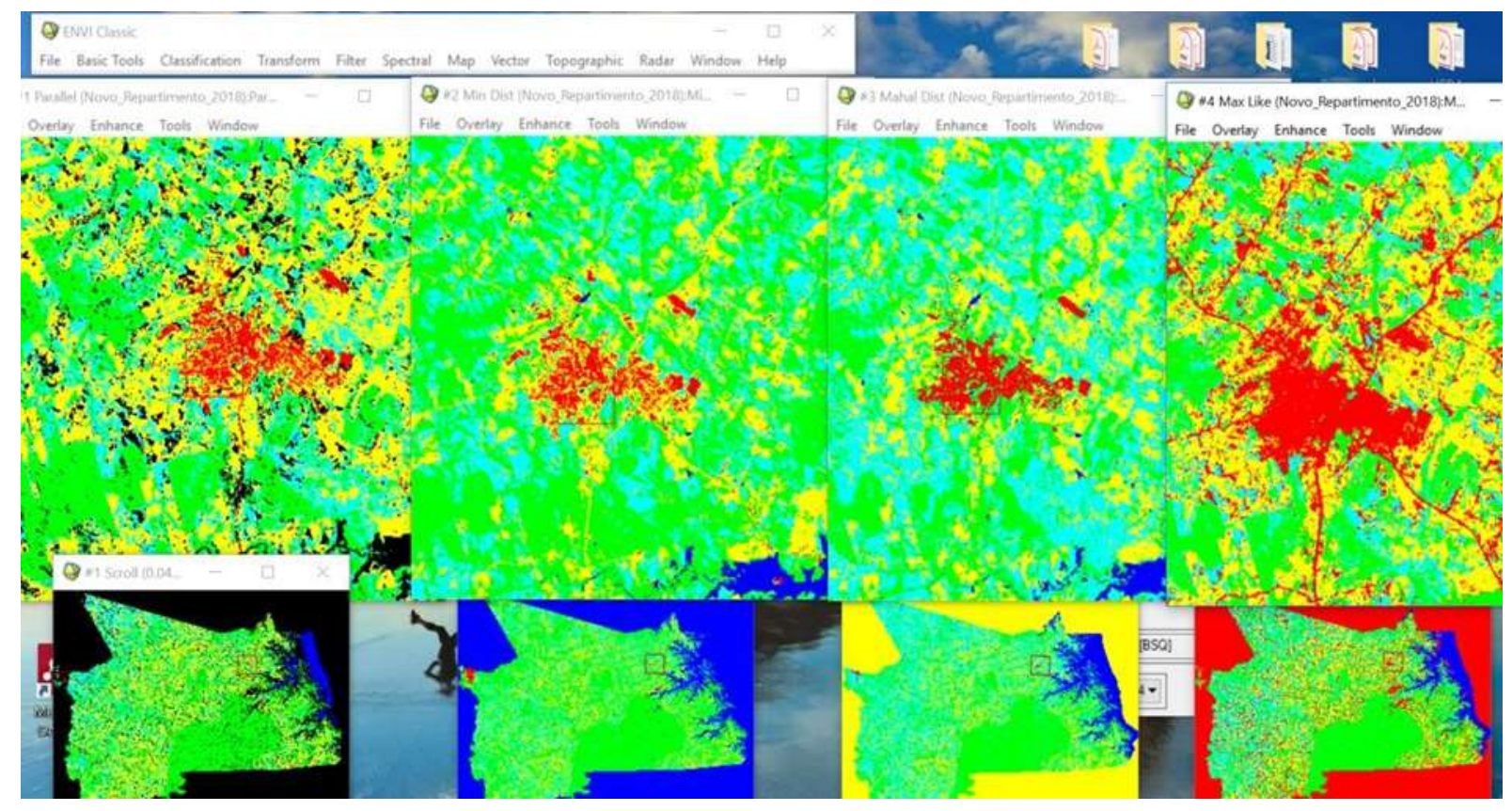

Fonte: Autores. 
Para o ano de 2019, foi utilizado as mesmas classes: Água, floresta, vegetação secundária, solo exposto e área antrópica. Foi construída a estatísticas das classes, para verificar quais bandas apresentavam a melhor resposta espectral da superfície e se as classes não estariam se confundindo, como segue na Figura 15. E seguiu-se os mesmos passos apresentadas acima.

Figura 15: Estatísticas de cada classe considerando as bandas para o ano de 2019.

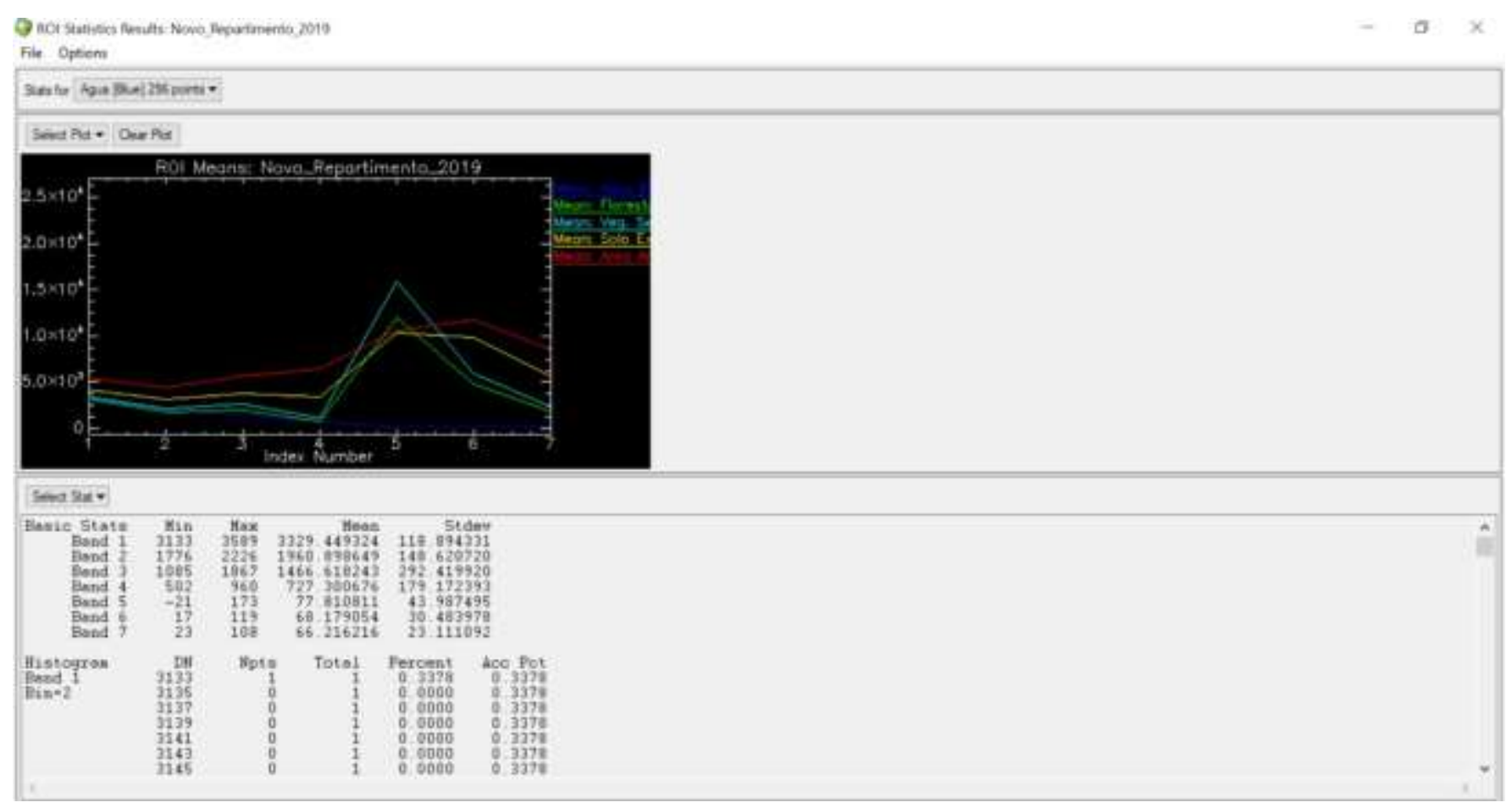

Fonte: Autores.

Com as amostras de cada classe coletada, foi realizado o processamento utilizando os 4 métodos já citados, resultando nas Figuras 16, 17, 18 e 19. 
Research, Society and Development, v. 11, n. 2, e5511222696, 2022

(CC BY 4.0) | ISSN 2525-3409 | DOI: http://dx.doi.org/10.33448/rsd-v11i2.22696

Figura 16: Método de paralelepípedo para o ano de 2019.

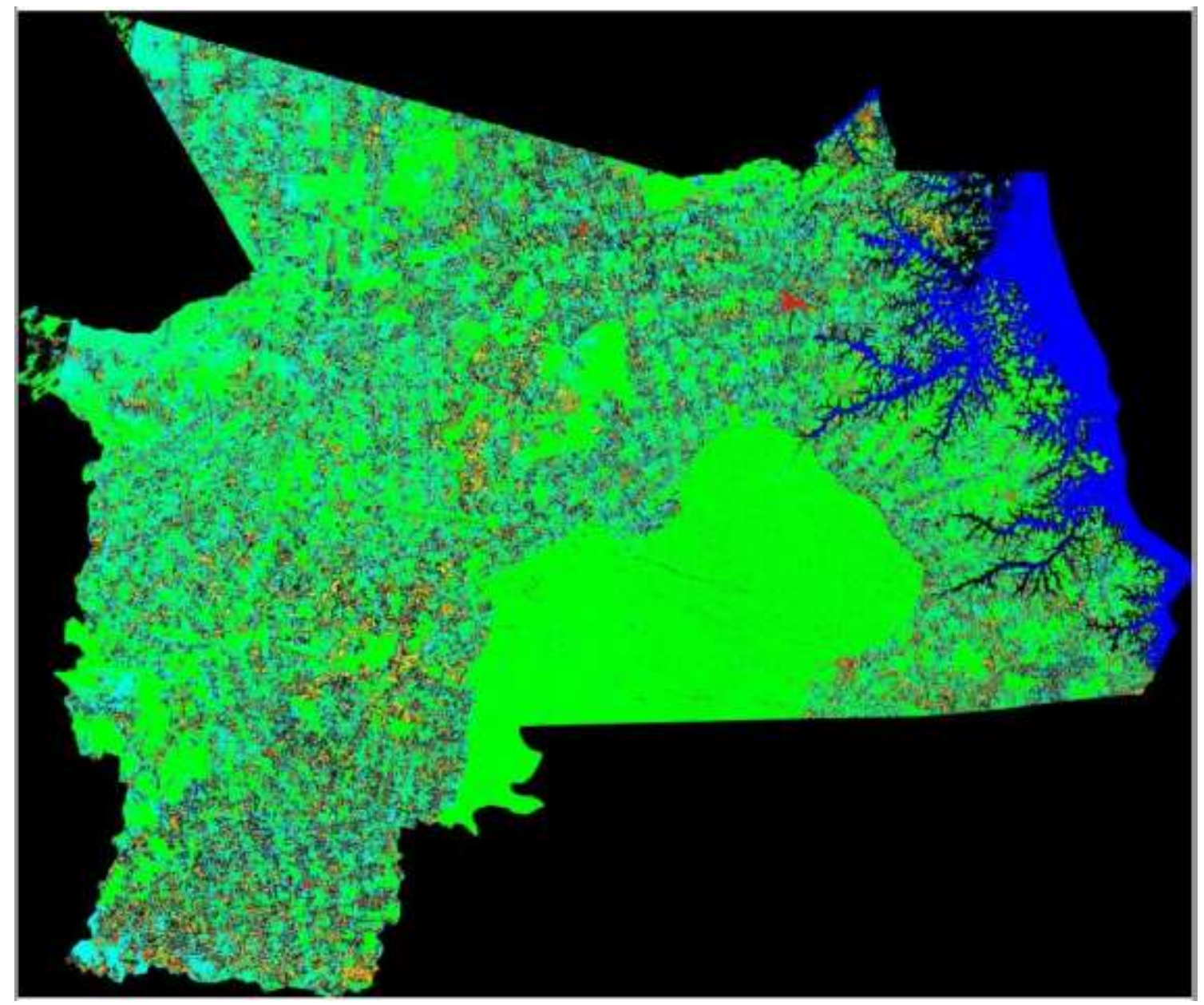

Fonte: Autores. 
Research, Society and Development, v. 11, n. 2, e5511222696, 2022

(CC BY 4.0) | ISSN 2525-3409 | DOI: http://dx.doi.org/10.33448/rsd-v11i2.22696

Figura 17: Método de mínima distância para o ano de 2019.

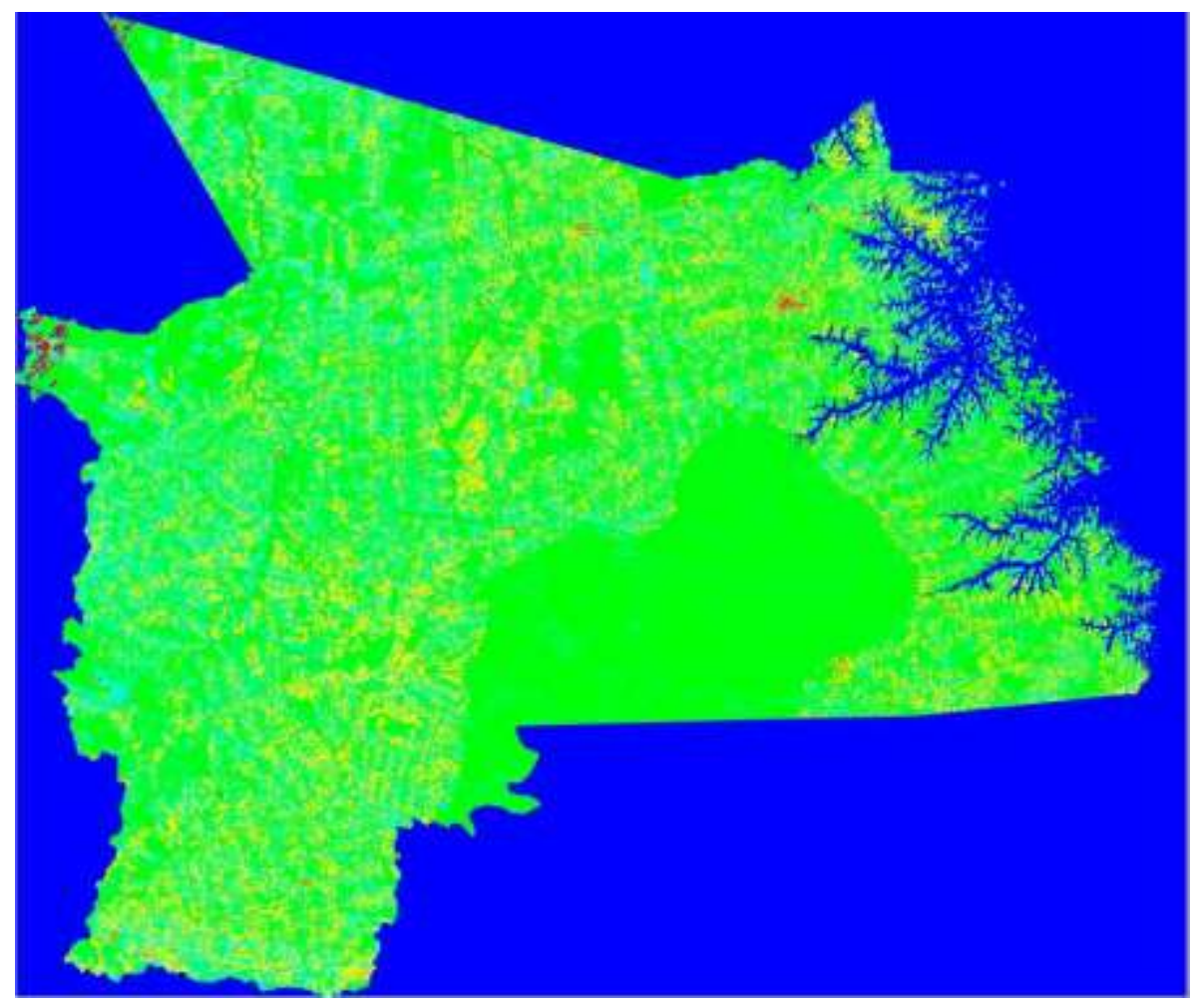

Fonte: Autores.

Figura 18: Método de Mahalanobis para o ano de 2019.

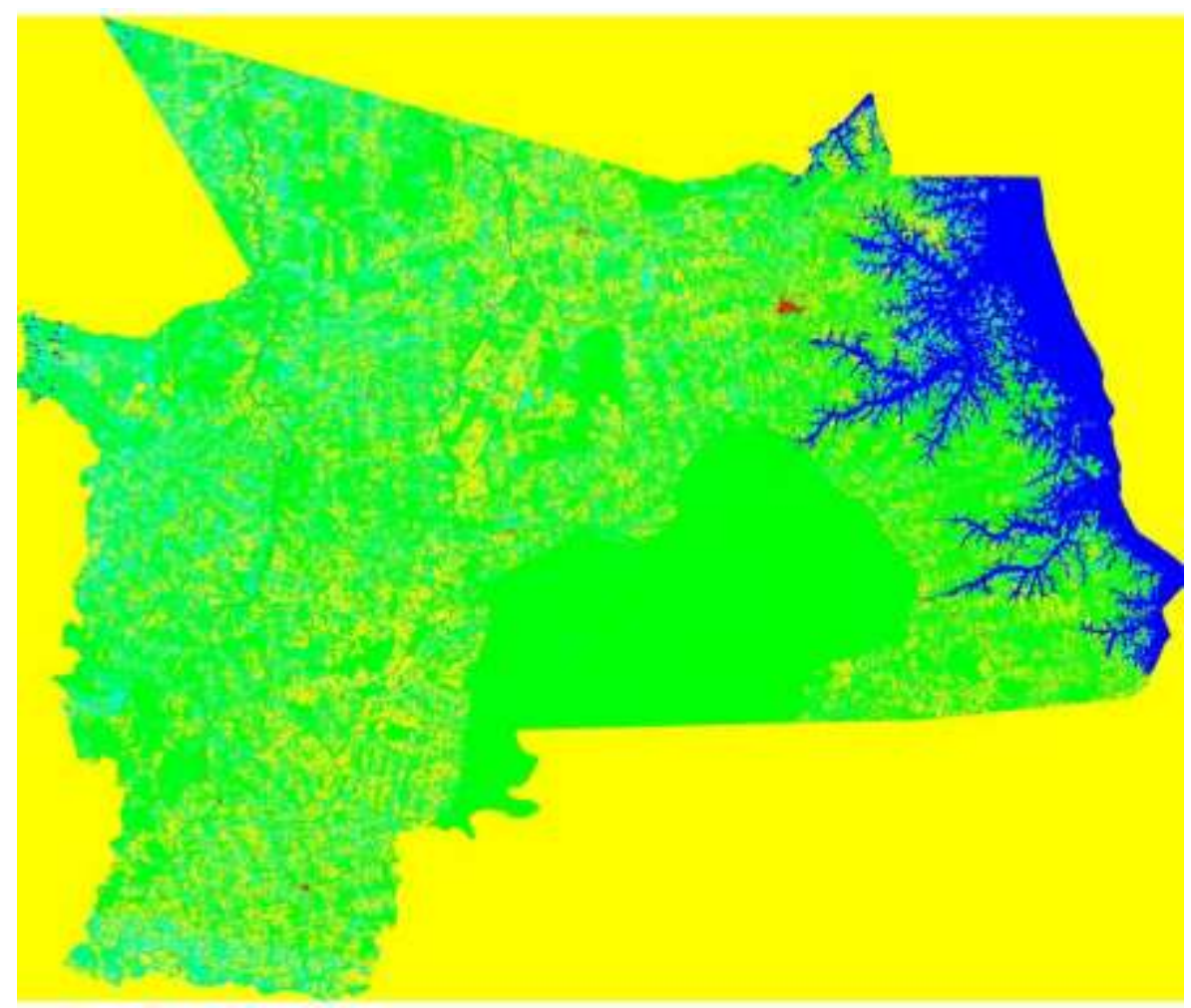

Fonte: Autores. 
Figura 19: Método de MaxVer para o ano de 2019.

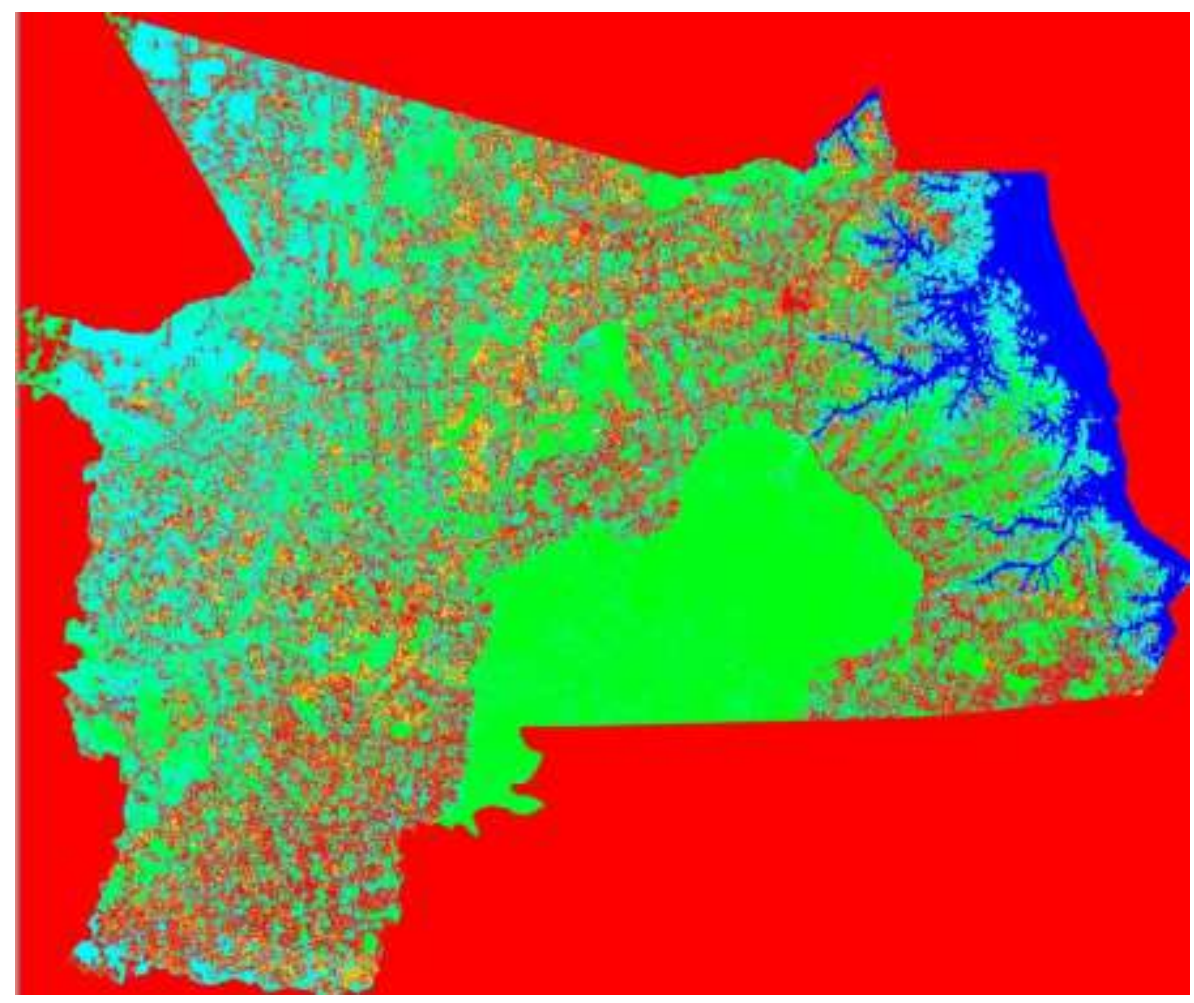

Fonte: Autores.

Para melhor representar os métodos, foi criado uma visualização simultânea, como segue na Figura 20.

Figura 20: Visualização simultânea dos 4 métodos para o ano de 2019.

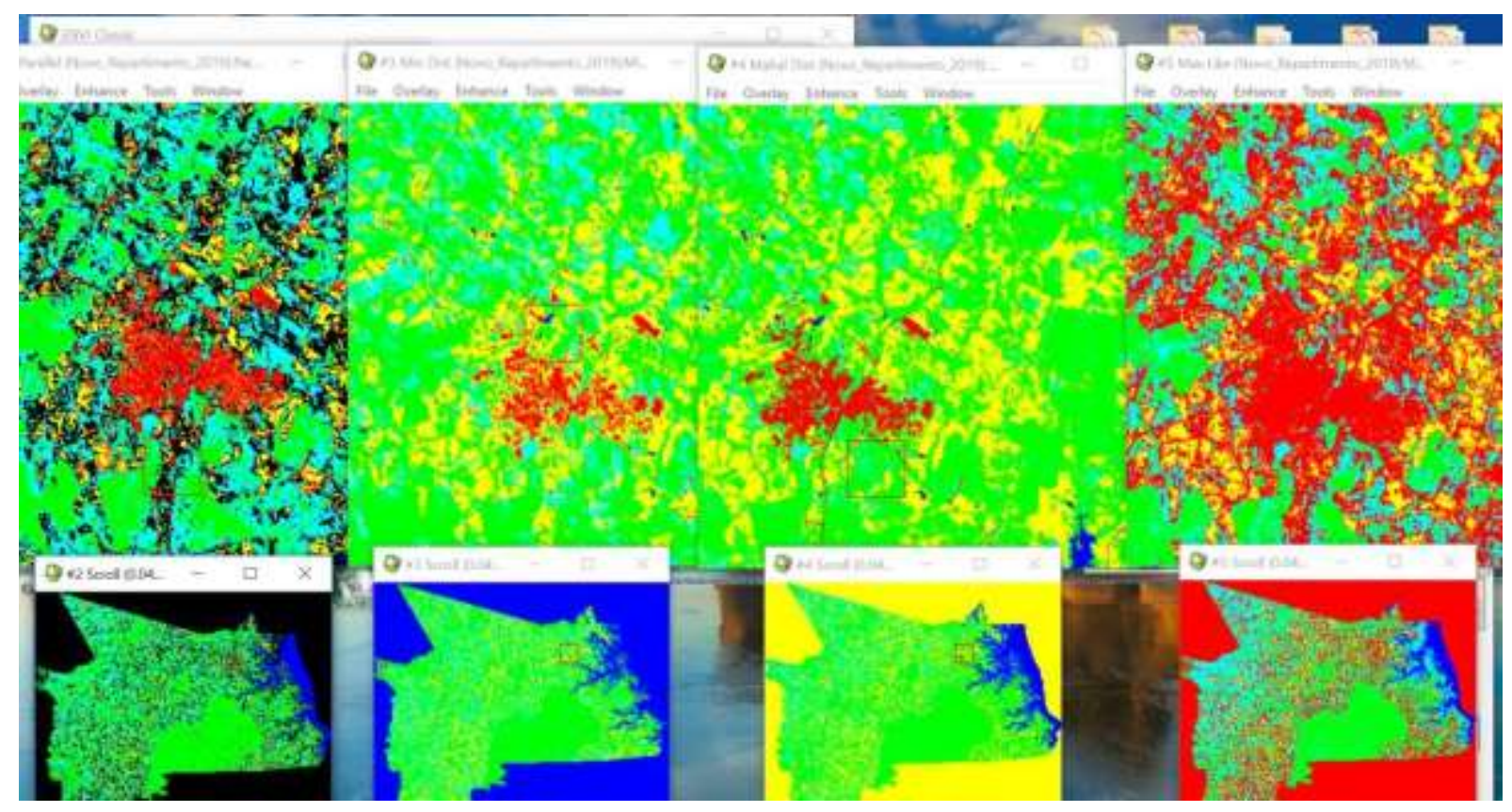

Fonte: Autores.

Escolhendo assim, o melhor método visual para se aplicar na área e fazer a análise de alteração da cobertura vegetal. Com isso, foi escolhido o método de Mahalanobis, apesar de muitos autores considerarem que o método de MaxVer é o mais completo de todas as classificações, para este trabalho não se mostrou eficiente por conta da confusão que 
a área antrópica estava apresentando com a coberta de nuvens, mais visível na classificação utilizando o método de MaxVer para o ano de 2019 (Figura 19).

Por isso, todos os dados estatísticos quantificados referentes aos anos de 2017, 2018 e 2019 para o trabalho (tabela 1,2 e 3) foram gerados a partir do método de Mahalanobis e expressos cartograficamente como segue nas Figuras 12, 21 e 22.

Tabela 1: Quantificação das classes para o ano de 2017.

\begin{tabular}{ccc}
\hline Classe & Área (ha) & Porcentagem \% \\
\hline Água & 129393,4103 & 8,407823607 \\
Floresta & 637827,5972 & 41,4452476 \\
Vegetação Secundária & 434520,5843 & 28,23460961 \\
Solo Exposto & 336055,1121 & 21,83644513 \\
Área Antrópica & 1167,67454 & 0,075874046 \\
Total & 1538964,378 & 100 \\
\hline
\end{tabular}

Fonte: Autores.

Figura 21: Mapa de classificação do ano de 2017.

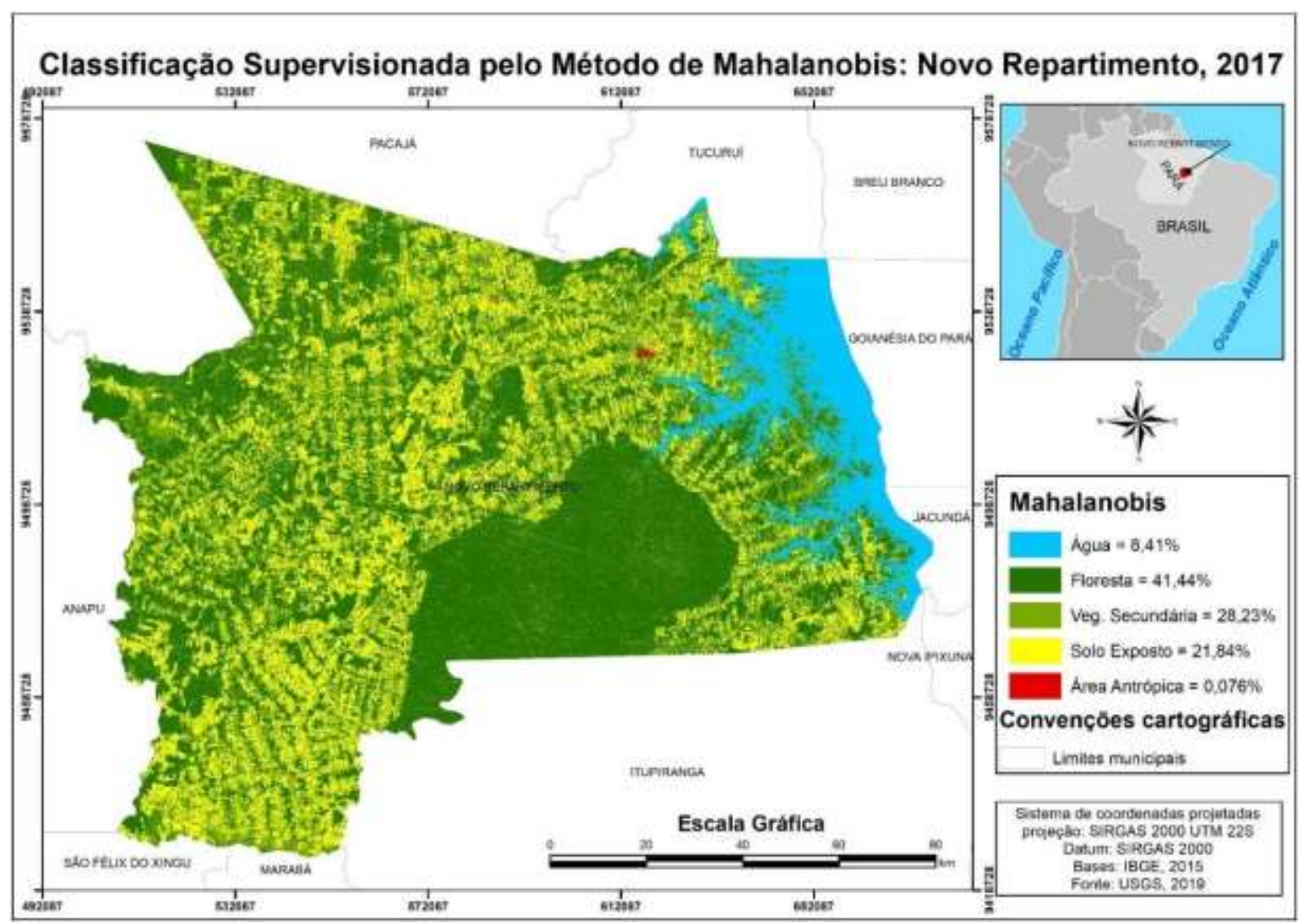

Fonte: Autores. 
Tabela 2: Quantificação das classes para o ano de 2018.

\begin{tabular}{ccc}
\hline Classe & Área (ha) & Porcentagem \% \\
\hline Água & 124066,9686 & 8,061718021 \\
Floresta & 627478,7797 & 40,77279426 \\
Vegetação Secundária & 538951,1315 & 35,02037728 \\
Solo Exposto & 246865,3723 & 16,04100626 \\
Área Antrópica & 1602,126208 & 0,104104177 \\
Total & 1538964,378 & 100 \\
\hline
\end{tabular}

Fonte: Autores.

Figura 22: Mapa de classificação do ano de 2018.

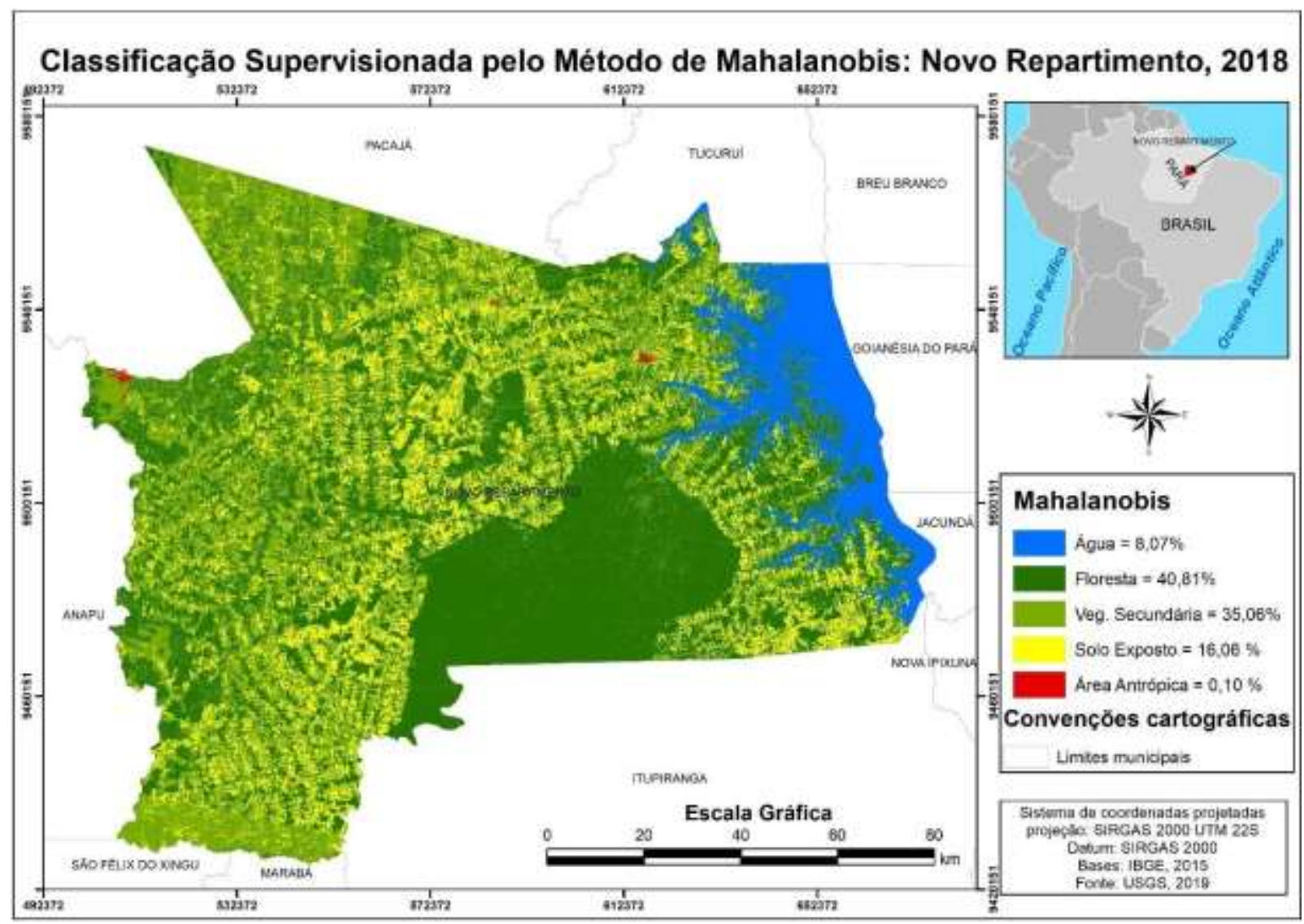

Fonte: Autores.

Tabela 3: Quantificação das classes para o ano de 2019.

\begin{tabular}{ccc}
\hline Classe & Área (ha) & Porcentagem \% \\
\hline Água & 124174,4514 & 8,068702 \\
Floresta & 917037,2954 & 59,58795 \\
Vegetação Secundária & 211545,5385 & 13,74597 \\
Solo Exposto & 283456,314 & 18,41864 \\
Área Antrópica & 2750,779208 & 0,178742 \\
Total & 1538964,378 & 100 \\
\hline
\end{tabular}


Figura 22: Mapa de classificação do ano de 2019.

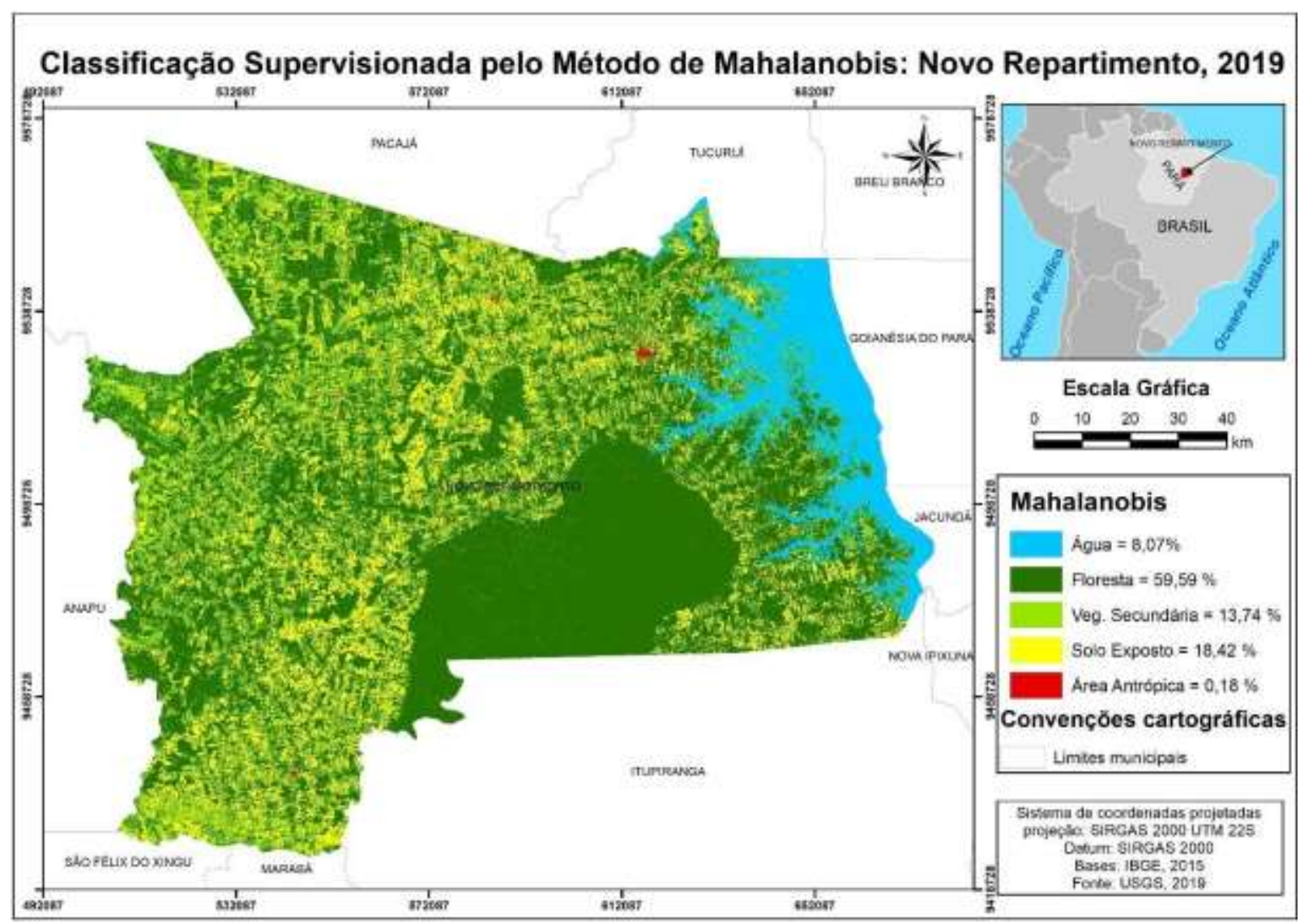

Fonte: Autores.

A primeira coisa a se chamar atenção é a área total do imóvel que não alcançou um número exato do limite municipal no formato vetor, mas esse erro pode ser vinculado a geração da classificação que foi feita a partir de imagem, ou seja, não sabe-se se ao realizar o recorte da área da imagem o algoritmo realmente considerou o limite e cortou pixels ao meio, ou se considerou o pixel todo. Mas destaca-se que a área a partir da classificação deu maior que o da geometria do shape da base do IBGE 2015.

A partir dessa observação, pode-se analisar de fato os dados encontrados no levantamento. Com o intuito de melhor representar os dados, foi criado o gráfico no Excel com a integração dos dados para verificar a ocorrência de variação na cobertura vegetal de cada classe em decorrência do ano de analise, como apresentado na Figura 23. 
Figura 23: Expressão gráfica das classes de mapeamento nos anos analisados.

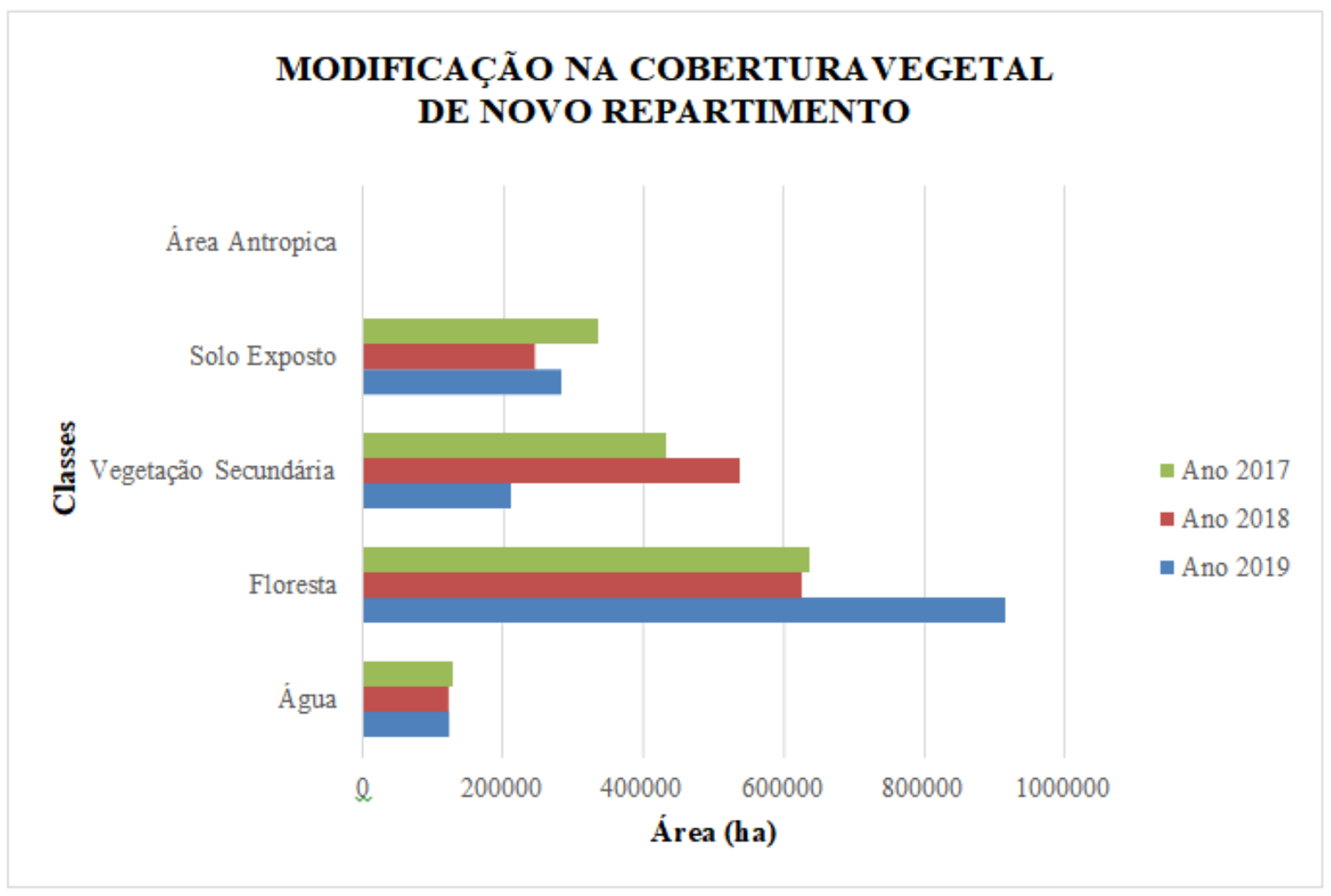

Fonte: Autores (2019).

Analisando a Figura 23 se tem a dimensão da variação, onde a classe de floresta apresenta uma instabilidade entre os anos, mas para o ano de 2019 se tem um aumento expressivo se considerar com os anos anteriores (2017 e 2018), assim como o aumento da floresta contribui para a diminuição de vegetação secundaria, demonstrando que a vegetação do município de Novo repartimento apresenta uma tendência de regeneração natural, com o ano a classe de vegetação secundaria migrando para a classe de floresta.

Isso é um avanço significativo para a conservação do meio ambiente, seja por conta das políticas públicas mais rigorosas ou pelo monitoramento continuo introduzido na Amazônia, principalmente nessa região do sudeste paraense que sofre grande pressão humana sobre os recursos naturais. Tem-se também indícios de diminuição do solo exposto, se manter a tendência, logo o solo exposto estará na fase de regeneração mais elevado.

A pesar da área antrópica não ter tido representatividade neste gráfico por conta dos valores das outras áreas, a classe apresentou o resultado esperado, como demonstrado na Figura 24. 
Figura 24: Expressão gráfica da classe de área antrópica.

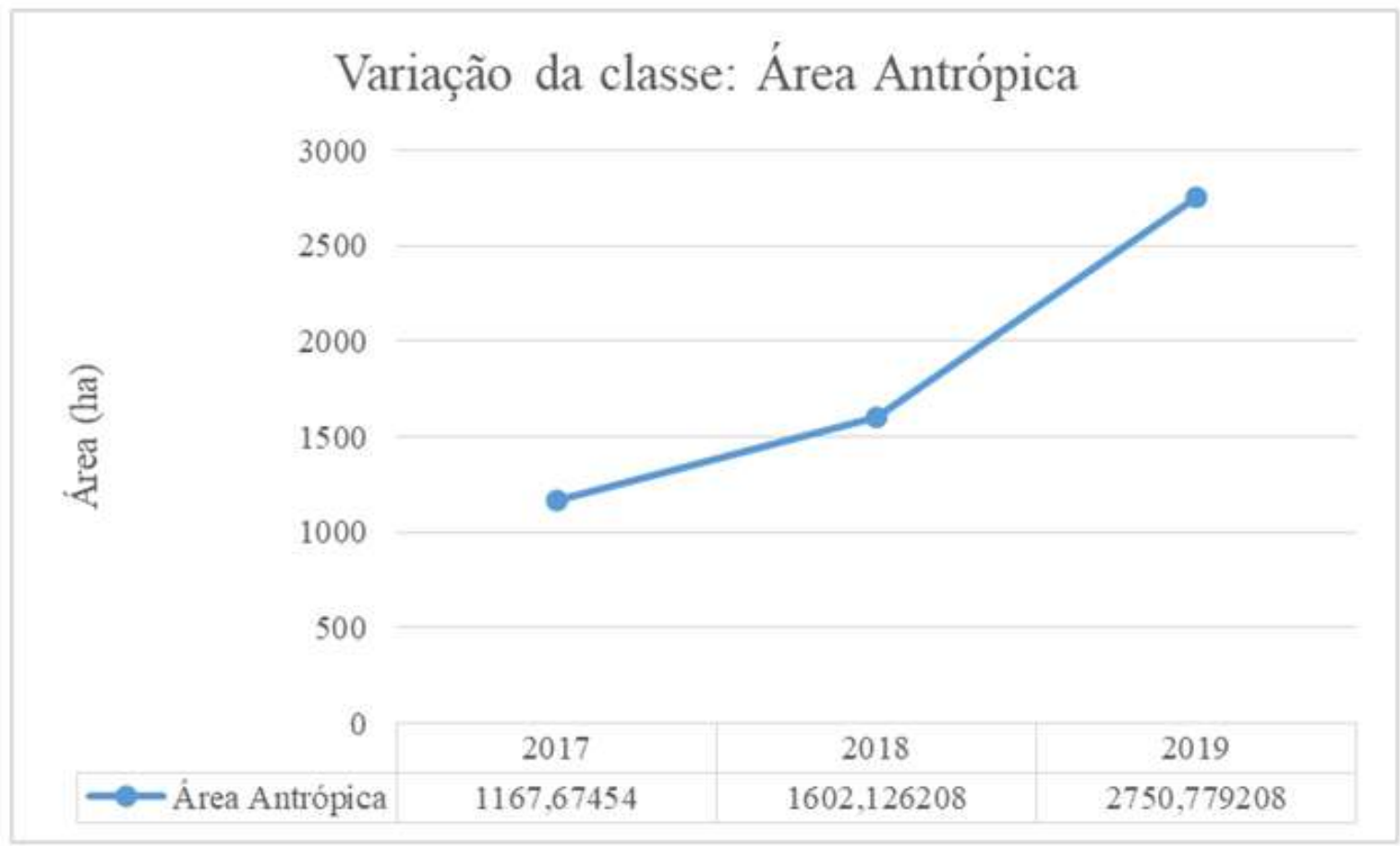

Fonte: Autores (2019).

Com isso, pode-se verificar o aumento de área antropizada que se dá graças ao aumento da população com o decorrer do tempo, uma tendência natural. Apesar do aumento da área antrópica se verifica o aumento da classe floresta, podendo se dizer que é um avanço na questão ambiental. Para apurar a analise, foi feito analise de dispersão (Figura 25).

Figura 25: Análise estatística dos dados.

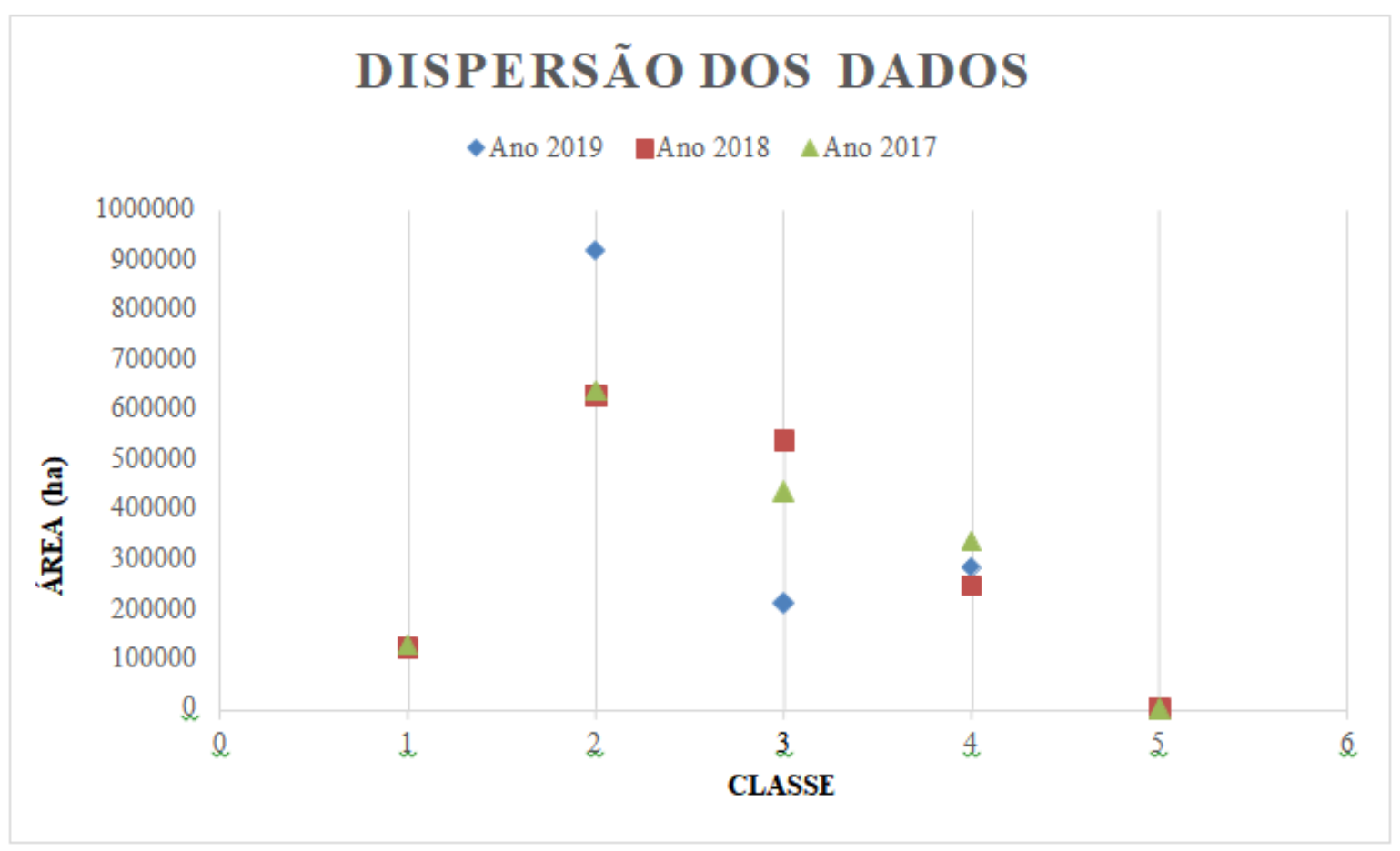

* 1 - água, 2 - floresta, 3 - vegetação secundária, 4 - solo exposto e 5 - área antrópica. Fonte: Autores. 
A classe de água e floresta tem dispersão quase nula se comparado com as outras em todos os anos. Já a classe floresta parenta uma dispersão mais acentuada no ano de 2019 que nos outros, enquanto a vegetação secundária apresenta dispersão em todos os anos e a classe de solo exposto aparece com dispersão relativamente baixa se comparada as outras classes mais significativas em transição.

Logo, pode-se concluir que a quantificação da floresta tem crescido com o tempo, refletindo na regeneração natural do ambiente. Enquanto que a vegetação secundária decresce no mesmo período, porque está incorporando a classe de floresta. Mas, tem-se o solo exposto diminuindo e a área antrópica crescendo.

\section{Conclusão}

Para a área em estudo a classificação mais indicada é de Mahanalobis, pois conseguiu distinguir bem a floresta da área de vegetação secundária, assim como a área antrópica de nuvem, apresentando muito bem as estradas que passam entre o município. Apesar das análises serem remotas, sem ida ao local, o trabalho obteve bons resultados e o aprendizado apurado do assunto.

Tendo destaque para as etapas de processamento, pela exigência de ser um trabalho mais apurado, refletindo em resultados coerentes, como a área antrópica aumentando, tendência natural dos municípios e a área de floresta se recuperando naturalmente, como indica por conta da diminuição de vegetação secundária e aumento de floresta, refletindo a regeneração natural.

O aumento da área de floresta pode ser consequência das políticas públicas implantadas na área ou por conta do monitoramento continuo e fiscalização por parte dos órgãos responsáveis. Como feito neste trabalho, possibilitando a quantificação e explanação de resultados palpáveis. Alcançando os objetivos aqui definidos.

\section{Referências}

Santana, A. L. S. \& Araújo, G. L. (2017). Erosão do solo em uma propriedade rural no município de Abre Campo (MG). III Seminário Científico da FACIG 09 e 10 de Novembro de 2017 II Jornada de Iniciação Científica da FACIG. file://C:/Users/franc/OneDrive/\%C3\%81rea\%20de\%20Trabalho/lix/368-1425-1PB.pdf.

Esri.- Esri Support 10.5 (10.5)". (2016). "New Esri ArcGIS Release Transforms Spatial Analytics" (Press release). https://www.esri.com/about/newsroom/announcements/new-esri-arcgis-release-transforms-spatial-analytics/.

Farias, M., Beltrão, N., Santos, C. A., \& Vasconcellos, R. C. (2015). A Dinâmica Do Desmatamento Da Amazônia: Análise Sobre O Município De Novo Repartimento $(\mathrm{Pa})$. Conference: $4^{\circ}$ Simpósio de Estudos e Pesquisas em Ciências Ambientais na Amazônia At: Universidade do Estado do Pará / CCNT. Conference: $4^{\circ}$ Simpósio de Estudos e Pesquisas em Ciências Ambientais na AmazôniaAt: Universidade do Estado do Pará / CCNT.

Farias, M. H. C. S. (2016). Contribuição de projetos de assentamentos para a dinâmica da mudança do uso da terra na Amazônia: um estudo em Novo Repartimento (PA). Belém, 2016. 106 f. Dissertação (Mestrado em Ciências Ambientais) - Universidade do Estado do Pará, Centro de Ciências Naturais e Tecnologia, Belém.

Farias,M. H. C. S., Santos, C. A., Beltrão, N. E. S., \& Silva, R. S. (2017). A Dinâmica Do Desmatamento Da Amazônia: Análise Sobre O Município De Novo Repartimento $(\mathrm{Pa})$. In Ciências ambientais e o desenvolvimento sustentável na Amazônia / Organizadores Adriane Theodoro Santos Alfaro, Daiane Garabeli Trojan. - Curitiba (PR): Atena editora.

Insituto Nacional de Pesquisas Espaciais -INPE. (2019). Metodologia Utilizada nos Projetos PRODES e DETER. http://www.obt.inpe.br/OBT/assuntos/programas/amazonia/prodes/pdfs/Metodologia_Prodes_Deter_revisada.pdf

Instituto Brasileiro de Geografia e Estatística-IBGE. (2021). Novo Repartimento. Portal do Governo Brasileiro. https://cidades.ibge.gov.br/brasil/pa/novorepartimento/panorama.

Instituto Brasileiro de Geografia e Estatística-IBGE. (2022). Biomas Brasileiros. IBGE educa Jovens. https://educa.ibge.gov.br/jovens/conheca-obrasil/territorio/18307-biomas-brasileiros.html.

Instituto Do Homem E Meio Ambiente Da Amazônia - IMAZON. (2018). Monitoramento Ambiental. https://imazon.org.br/programas/monitoramento-daamazonia/.

Instituto Nacional De Pesquisas Espaciais - INPE. (2008). Manuais: tutorial de geoprocessamento SPRING.

Ipam Amazônia. (2015). Arco do desmatamento. https://ipam.org.br/glossario/arco-do-desmatamento/. 
Research, Society and Development, v. 11, n. 2, e5511222696, 2022

(CC BY 4.0) | ISSN 2525-3409 | DOI: http://dx.doi.org/10.33448/rsd-v11i2.22696

Kawakubo, F. S. (2019). Sensoriamento Remoto Aplicado à Geografia: Comportamento Espectral dos Objetos. https://edisciplinas.usp.br/pluginfile.php/2197878/mod_resource/content/1/Aula4SR.pdf

Mahalanobis, P C. (1936). On the generalised distância in statistics. Proceedings of the National Institute of Sciences of India. 2 (1): 49-55.

Meneses, Paulo Roberto \& Almeida, Tati De. (2012). Introdução ao Processamento de Imagens de Sensoriamento Remoto. https://www.researchgate.net/publication/332292728_INTRODUCAO_AO_PROCESSAMENTO_DE_IMAGENS_DE_SENSORIAMENTO_REMOTO

Passos, M. M. (2017). BR-163, de Cuiabá a Santarém: o papel dos agentes e sujeitos no ordenamento do território e na implementação de políticas públicas. Ciencia Trópico. 41(1), 139-164.

Souza Filho, P. W. M., Paradella, W. R., Souza Júnior, C., Valeriano, D. M., \& Miranda, F. P. (2006). Sensoriamento remoto e recursos naturais da amazônia. Ciencia e cultura. 58(3). http://cienciaecultura.bvs.br/pdf/cic/v58n3/a16v58n3.pdf

Ribeiro, A. (2022). "Agricultura intensiva e meio ambiente", Brasil Escola. https://brasilescola.uol.com.br/geografia/agricultura-intensiva-meio-ambiente.htm.

Ribeiro, E. S., Faro, B. L. S. O., Nascimento, R. S. C., Carneiro, F. S., Amaral, A. P. M., Bezerra, M. G. S., Amorim, M. B., \& Garcia, T. S. (2021). Avaliação multitemporal da cobertura vegetal da reserva biológica de Tapirapé, Pará. Research, Society And Development, 10 , e50910414345.

Rosário, J. T. C. (2020). Desmatamento no estado do Pará: Causas e efeitos versus as ações de combate realizadas pela Polícia Civil. Dissertação apresentada ao Programa de PósGraduação em Segurança Pública, do Instituto de Filosofia e Ciências Humanas, da Universidade Federal do Pará. 174p.

Rosário, R. R., Barbosa, M. T., Carneiro, F. S., \& Costa, M. S. S. (2021). Uso e ocupação do solo do município de novo progresso no Estado do Pará-Brasil. Research, Society And Development, 10, e51210112060-e51210112060.

Souza, C. B. G., Carneiro, F. S., Rodrigues, H. C. T., Ribeiro, E. G. P., Amaral, A. P. M., Silva, J. S. L. P., Araujo, S. C. A., \& Castro, C. V. B. (2021). Análise espaço-temporal de Área de Proteção Permanente para a gestão ambiental municipal em Parauapebas no estado do Pará-Brasil. Research, Society And Development, v. 10, p. e24110615491.

SulSoft - Soluções em processamento de dados geoespaciais. (2022). Conheça O Envi 5.6. http://www.envi.com.br/envi.php.

Tavares, L. C., Costa, J. A., Araujo, A. R. R., Garcia, F. H. M., Carneiro, F. S., Amaral, A. P. M., Braga, E. O. \& Garcia, T. S. (2021). O uso do índice de vegetação por diferença normalizada na análise multitemporal da cobertura vegetal no complexo industrial do município de Barcarena?Pará-Brasil. Research, Society And Development, 10, e23010715470. 